\title{
OPEN Study of gadolinium substitution effects in hexagonal yttrium manganite $\mathrm{YMnO}_{3}$
}

\author{
Dovydas Karoblis $^{1}$, Aleksej Zarkov ${ }^{1 凶}$, Edita Garskaite², Kestutis Mazeika ${ }^{3}$, Dalis Baltrunas ${ }^{3}$, \\ Gediminas Niaura ${ }^{4,5}$, Aldona Beganskiene ${ }^{1}$ \& Aivaras Kareiva $^{1}$
}

In the present work, gadolinium substitution effects on the properties of yttrium manganite $\mathrm{Y}_{\mathrm{x}} \mathrm{Gd}_{1-\mathrm{x}} \mathrm{Mn}_{0.97} \mathrm{Fe}_{0.03} \mathrm{O}_{3}$ ( $\mathrm{x}$ from 0 to 1 with a step of 0.2 ) synthesized by an aqueous sol-gel method have been investigated. Partial substitution of $\mathrm{Mn}^{3+}$ by ${ }^{57} \mathrm{Fe}^{3+}$ in the manganite was also performed in order to investigate deeper the structural properties of synthesized compounds applying Mössbauer spectroscopy. It was demonstrated that substitution of $\mathrm{Y}^{3+}$ by $\mathrm{Gd}^{3+}$ ions leads to the changes of structural, magnetic and morphological properties of investigated system. The crystal structure gradually transformed from hexagonal to orthorhombic with an increase of $\mathrm{Gd}^{3+}$ content in the crystal lattice. The mixed phase was obtained when $x=0.6$, whereas other compounds were determined to be monophasic. Magnetization measurements revealed paramagnetic behavior of all specimens, however magnetization values were found to be dependent on chemical composition of the samples. Solid solutions with orthorhombic structure revealed higher magnetization values compared to those of hexagonal samples. The highest magnetization was observed for pure $\mathrm{GdMn}_{0.97} \mathrm{Fe}_{0.03} \mathrm{O}_{3}$. Structural properties were investigated by powder X-ray diffraction, Mössbauer, FTIR and Raman spectroscopies. Morphological features of the synthesized specimens were studied by scanning electron microscopy (SEM).

Perovskite-type lanthanide manganites $\mathrm{LnMnO}_{3}$ ( $\mathrm{Ln}$-lanthanide element) have attracted a lot of interest due to their unique properties including colossal magnetoresistance and multiferroicity ${ }^{1,2}$. These compounds could be used as microwave phase shifters, cooling materials as well as applied in photovoltaic solar cells ${ }^{3}$. Depending on lanthanide element, there are two possible perovskite structures: noncentrosymmetric hexagonal (for $\mathrm{Ln}=\mathrm{Ho}-\mathrm{Lu}$ ) and orthorhombic (for $\mathrm{Ln}=\mathrm{La}-\mathrm{Dy})^{4}$. Under certain temperature and pressure one structure can be transformed to another and vice versa ${ }^{5,6}$. Those two perovskite phases demonstrate different magnetic configurations and electric polarization, which is higher in hexagonal structure ${ }^{7}$.

$\mathrm{YMnO}_{3}$ can be obtained in both crystal structures: thermodynamically stable hexagonal and metastable orthorhombic structure. Hexagonal $\mathrm{YMnO}_{3}$ is known as a single-phase multiferroic material with room-temperature ferroelectricity $\left(\mathrm{T}_{\mathrm{c}} \approx 900 \mathrm{~K}\right)$ and low-temperature antiferromagnetism $\left(\mathrm{T}_{\mathrm{N}} \approx 70 \mathrm{~K}\right)^{8,9}$. Orthorhombic $\mathrm{YMnO}_{3}$ is also considered as multiferroic at low temperatures, however it is characterized by lower electric polarization ${ }^{10}$. In addition to ferroelectric and antiferromagnetic properties, hexagonal $\mathrm{YMnO}_{3}$ is a narrow-band gap semiconductor, which can be utilized as photocatalyst for the degradation of organic pollutants under ultraviolet and visible light irradiation and gas sensing application ${ }^{11-13}$. According to literature, $\mathrm{YMnO}_{3}$ with orthorhombic structure can be prepared by a number of synthetic approaches such as mechanochemical synthesis ${ }^{14}$, epitaxial strain $^{15}$ or other low-temperature syntheses ${ }^{16}$. For the preparation of hexagonal $\mathrm{YMnO}_{3}$ few synthesis methods were also reported, including sol-gel ${ }^{17}$, solid-state ${ }^{18}$, hydrothermal ${ }^{19}$, polymerized complex method ${ }^{20}$ and glycine-nitrate combustion ${ }^{21}$.

Orthorhombic $\mathrm{GdMnO}_{3}$ is another multiferroic rare-earth manganite, which shows few temperature-dependent magnetic transitions (from paramagnetic to antiferromagnetic collinear at $44 \mathrm{~K}$, changing to A type antiferromagnetic at $23 \mathrm{~K}$ and weak ferromagnetism below $6 \mathrm{~K})^{22}$ and large spontaneous polarization $\mathrm{Pa} \sim 4900 \mu \mathrm{C} /$ $\mathrm{m}^{2}$ for thin films ${ }^{23}$. Hexagonal phase of this compound can be stabilized only in the form of epitaxial thin film,

${ }^{1}$ Institute of Chemistry, Vilnius University, Naugarduko 24, 03225 Vilnius, Lithuania. ${ }^{2}$ Wood Science and Engineering, Department of Engineering Sciences and Mathematics, Luleå University of Technology, Forskargatan 1, 93187 Skellefteå, Sweden. ${ }^{3}$ Center for Physical Sciences and Technology, 02300 Vilnius, Lithuania. ${ }^{4}$ Department of Organic Chemistry, Center for Physical Sciences and Technology, Sauletekio Ave. 3, 10257 Vilnius, Lithuania. ${ }^{5}$ Institute of Chemical Physics, Faculty of Physics, Vilnius University, Sauletekio Ave. 3, 10257 Vilnius, Lithuania. ${ }^{\square}$ email: aleksej.zarkov@chf.vu.It 
which was characterized by enhanced ferromagnetic properties ${ }^{24}$. Furthermore, this compound has high magnetoelectric coefficient and possesses pyroelectric properties ${ }^{25,26}$. For the preparation of $\mathrm{GdMnO}_{3}$ compound sol-gel ${ }^{27}$, solid-state ${ }^{28}$, sol-gel combustion ${ }^{29}$ and co-precipitation ${ }^{30}$ methods were previously applied.

There are few studies considering synthesis and characterization of $\mathrm{Y}_{\mathrm{x}} \mathrm{Gd}_{1-\mathrm{x}} \mathrm{MnO}_{3}$ system ${ }^{31-35}$. Vilarinho et al. ${ }^{33}$ and Bos et al. ${ }^{35}$ demonstrated the formation of $\mathrm{Y}_{\mathrm{x}} \mathrm{Gd}_{1-\mathrm{x}} \mathrm{MnO}_{3}$ solid solutions in a whole compositional range, while others investigated dielectric, magnetic and ferroelectric properties of Gd-rich orthorhombic compounds with $\mathrm{x} \leq 0.4^{31,32,34}$. It was observed that partial substitution of $\mathrm{Gd}^{3+}$ by $\mathrm{Y}^{3+}$ can lead to the stabilization of ferroelectric phase when $\mathrm{x}=0.1$. Furthermore, when $\mathrm{x}>0.1$ weak ferromagnetic character disappears and antiferromagnetic ordering is established ${ }^{34}$. The monophasic $\mathrm{Y}_{\mathrm{x}} \mathrm{Gd}_{1-\mathrm{x}} \mathrm{MnO}_{3}$ and related systems could be employed to study and understand the charge transport across the interfaces, to investigate deeper spin-disorder state near nonmagnetic impurities, to determine substitutional-driven structure-ferroelectricity relationship and other fundamental physical properties of such complex oxides. These new knowledges obtained could be used in future for the construction of specific functionalities in novel ferroelectrics.

In this work, the solid solutions of $\mathrm{Y}_{\mathrm{x}} \mathrm{Gd}_{1-\mathrm{x}} \mathrm{Mn}_{0.97} \mathrm{Fe}_{0.03} \mathrm{O}_{3}(\mathrm{x}=0-1$ with a step of 0.2$)$ with partial substitution of $\mathrm{Mn}^{3+}$ by $\mathrm{Fe}^{3+}$ ( or by ${ }^{57} \mathrm{Fe}^{3+}$ ) ions were prepared for the first time by our best knowledge using environmentally friendly and simple sol-gel technique. Partial substitution of $\mathrm{Mn}^{3+}$ by ${ }^{57} \mathrm{Fe}^{3+}$ in the manganites was performed in order to investigate deeper the structural and magnetic properties of synthesized compounds applying Mössbauer spectroscopy. The dependence and evolution of structural, magnetic and morphological properties on chemical composition were investigated and discussed herein.

\section{Materials and methods}

Synthesis. Synthesis of all samples was performed by sol-gel method using modified previously reported procedure ${ }^{36}$. For the preparation of $\mathrm{Y}_{\mathrm{x}} \mathrm{Gd}_{1-\mathrm{x}} \mathrm{Mn}_{0.97} \mathrm{Fe}_{0.03} \mathrm{O}_{3}$ series by changing $\mathrm{x}$ from 0 to 1 with a step of 0.2 ,

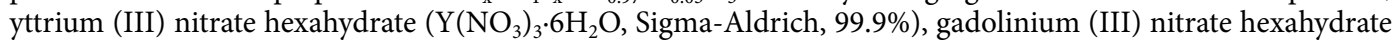
$\left(\mathrm{Gd}\left(\mathrm{NO}_{3}\right)_{3} \cdot 6 \mathrm{H}_{2} \mathrm{O}\right.$, Sigma-Aldrich, 99.99\%), manganese (II) nitrate tetrahydrate $\left(\mathrm{Mn}\left(\mathrm{NO}_{3}\right)_{2} \cdot 4 \mathrm{H}_{2} \mathrm{O}\right.$, Alfa Aesar, 99.9\%) and iron powders (Fe, Carl Roth, 99.5\%) were used as the starting materials. Firstly, iron powders were dissolved in $6 \mathrm{M}$ nitric acid $\left(\mathrm{HNO}_{3}\right.$, Carl Roth, 65\%) and citric acid monohydrate $\left(\mathrm{C}_{6} \mathrm{H}_{8} \mathrm{O}_{7} \cdot \mathrm{H}_{2} \mathrm{O}\right.$, Chempur, 99.9\%) was separately dissolved in $20 \mathrm{ml}$ of distilled water. After the dissolution of citric acid, all metal nitrates and required aliquot of iron solution were added. Next, the obtained mixture was heated on a hot plate at $90{ }^{\circ} \mathrm{C}$ under constant stirring until a clear and transparent solution was obtained. After it, an appropriate amount of ethylene glycol $\left(\mathrm{C}_{2} \mathrm{H}_{6} \mathrm{O}_{2}\right.$, Sigma-Aldrich, $\left.\geq 99.5 \%\right)$ was added to the above solution (total metal ions to citric acid to ethylene glycol molar ratio was 1:3:10). The obtained liquid precursor was homogenized under constant stirring at $90^{\circ} \mathrm{C}$ for $1.5 \mathrm{~h}$. For the formation of the gel the temperature of magnetic stirrer was increased to $150{ }^{\circ} \mathrm{C}$, which led to the evaporation of water. The resulted gel was dried in the oven at $140^{\circ} \mathrm{C}$ for $12 \mathrm{~h}$, ground in agate mortar and annealed at $1100{ }^{\circ} \mathrm{C}$ for $5 \mathrm{~h}$ in air with a heating rate of $5^{\circ} \mathrm{C} / \mathrm{min}$. Identical synthesis procedure was applied for the preparation of $\mathrm{Y}_{\mathrm{x}} \mathrm{Gd}_{1-\mathrm{x}} \mathrm{Mn}_{0.97} \mathrm{Fe}_{0.03} \mathrm{O}_{3}\left(\mathrm{x}=0.0,0.4\right.$ and 1.0) samples with ${ }^{57} \mathrm{Fe}$. These specimens were used only for Mössbauer spectroscopy measurements.

Characterization. Thermal decomposition of precursor gels was investigated by thermogravimetric and differential scanning calorimetric (TG/DTG/DSC) analysis using PerkinElmer STA 6000 Simultaneous Thermal Analyzer. About 5-10 mg of dried sample was heated from $30{ }^{\circ} \mathrm{C}$ to $900{ }^{\circ} \mathrm{C}$ at $10{ }^{\circ} \mathrm{C} / \mathrm{min}$ heating rate in a dry flowing air $(20 \mathrm{~mL} / \mathrm{min})$. X-ray diffraction (XRD) analysis was performed with Rigaku Miniflex II diffractometer using a primary beam $\mathrm{Cu}$ Ka radiation $\left(\lambda=1.541838 \AA\right.$ ) in $2 \theta$ range from $10^{\circ}$ to $70^{\circ}$ with a step of $0.02^{\circ}$ and scanning speed of $2 \% \mathrm{~min}$. The obtained diffraction data were refined by the Rietveld method using the Fullprof suite. PerkinElmer FT-IR spectrometer was used for FT-IR analysis of compounds. All spectra were recorded at ambient temperature in the range of $4000-400 \mathrm{~cm}^{-1}$. Raman spectra were recorded using inVia Raman (Renishaw, United Kingdom) spectrometer equipped with thermoelectrically cooled $\left(-70^{\circ} \mathrm{C}\right) \mathrm{CCD}$ camera and microscope. Raman spectra were excited with $532 \mathrm{~nm}$ beam from the CW diode pumped solid state (DPSS) laser (Renishaw, UK). The laser power at the sample was restricted to $0.6 \mathrm{~mW}$ to avoid laser-induced sample heating and photodegradation. The $20 \times / 0.40$ NA objective was used during all the measurements. The overall integration time was $400 \mathrm{~s}$. Position of the Raman bands on the wavenumber axis was calibrated by the polystyrene film standard spectrum. Parameters of the bands were determined by fitting the experimental spectra with Gaussian-Lorentzian shape components using GRAMS/Al 8.0 (Thermo Scientific, USA) software. The morphology of samples was investigated using a scanning electron microscope (SEM) Hitachi SU-70. Grain size distribution was estimated from SEM micrographs using ImageJ software. Magnetometer consisting of the lock-in amplifier SR510 (Stanford Research Systems), the gauss/teslameter FH-54 (Magnet Physics) and the laboratory magnet supplied by the power source SM 330-AR-22 (Delta Elektronika) was used to record magnetization dependences on applied magnetic field. Mössbauer spectra were measured using ${ }^{57} \mathrm{Co}(\mathrm{Rh})$ source and Mössbauer spectrometer (Wissenschaftliche Elektronik $\mathrm{GmbH})$ at room $(\approx 296 \mathrm{~K})$ temperature and within 10-70 K temperature range. Closed cycle He cryostat (Advanced Research Systems) was applied for low temperature measurements. The doublets, sextets, quadrupole splitting and hyperfine field distributions, and Hamiltonian method were used to fit to Mössbauer spectra applying WinNormos Site and Dist software. Combined quadrupole and magnetic dipole interactions were described using Hamiltonian method applying the parameters: hyperfine field $B$, term (main component) of quadrupole interaction $e Q V_{z z} / 2$, asymmetry parameter $\eta$, and the angles $\theta$ and $\varphi$. $Q$ is nuclear quadrupole moment and $V_{z z}$ is $z$ component of electric field gradient (EFG) diagonalized tensor choosing the principal axis system so that $\left|V_{z z}\right| \geqslant\left|V_{x x}\right| \geqslant\left|V_{y y}\right|^{37}$. The asymmetry parameter $\eta=\left(V_{x x}-V_{y y}\right) / V_{z z}$. The angle $\theta$ is between magnetization direction and EFG $z$ axis while the angle $\varphi$ is between magnetization projection into the $x y$ plane and EFG $x$ axis. In case of pure quadrupole or magnetic dipole interactions the param- 


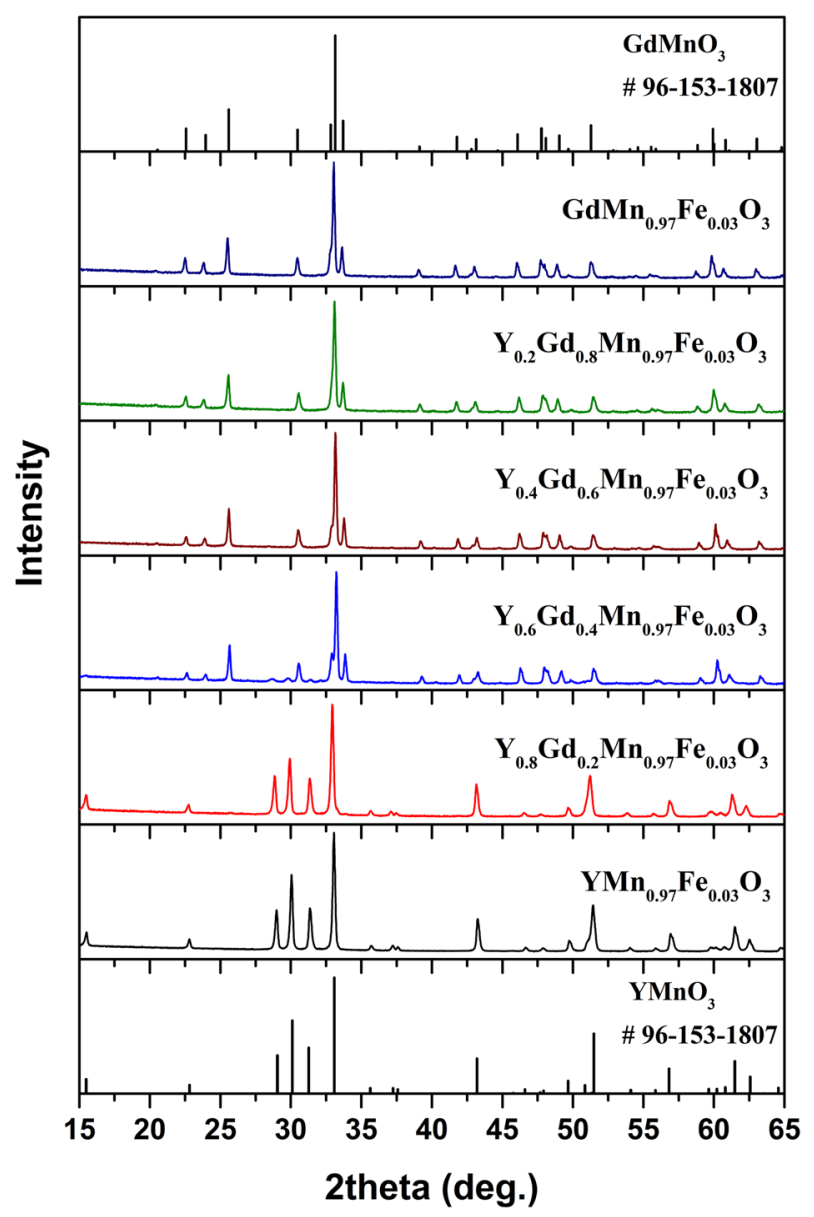

Figure 1. $\mathrm{XRD}$ patterns of $\mathrm{Y}_{\mathrm{X}} \mathrm{Gd}_{1-\mathrm{x}} \mathrm{Mn}_{0.97} \mathrm{Fe}_{0.03} \mathrm{O}_{3}$ samples.

eters of doublets and sextets, respectively, are determined by simple solution of Hamiltonian. The quadrupole splitting of doublet which is observed in paramagnetic state when $B=0$ is defined by:

$$
\Delta=\frac{e Q V_{z z}}{2}\left(1+\frac{\eta}{3}^{2}\right)^{1 / 2}
$$

When the quadrupole shifts $\varepsilon$ of sextets lines defined by hyperfine magnetic field $B$ are small they can be approximated by first order correction:

$$
2 \varepsilon=\frac{e Q V_{z z}}{4}\left(3 \cos ^{2} \theta-1+\eta \sin ^{2} \theta \cos 2 \varphi\right)
$$

The outer lines of sextet shift by $+\varepsilon$, i.e. in different direction than inner four lines shifting by $-\varepsilon$.

The influence of quadrupole and magnetic dipole interactions was of comparable strength in case of $\mathrm{YMn}_{0.97} \mathrm{Fe}_{0.03} \mathrm{O}_{3}$. Therefore, direct solution Hamiltonian was used for $\mathrm{YMn}_{0.97} \mathrm{Fe}_{0.03} \mathrm{O}_{3}$ at low temperature. For Mössbauer measurements $3 \mathrm{~mol} \%$ of $\mathrm{Mn}$ was substituted by $\mathrm{Fe}\left(90 \%\right.$ enriched with $\left.{ }^{57} \mathrm{Fe}\right)$. Because of exchange interactions iron atoms generally reflect magnetic ordering and dynamics of Mn spins in studied manganites ${ }^{38-43}$.

\section{Results and discussion}

The XRD patterns of $\mathrm{Y}_{\mathrm{x}} \mathrm{Gd}_{1-\mathrm{x}} \mathrm{Mn}_{0.97} \mathrm{Fe}_{0.03} \mathrm{O}_{3}$ samples annealed at $1100^{\circ} \mathrm{C}$ are represented in Fig. 1 . As was mentioned previously, few possible structures can be observed for $\mathrm{YMnO}_{3}$. In our case, high annealing temperature resulted in the formation of hexagonal $\mathrm{YMn}_{0.97} \mathrm{Fe}_{0.03} \mathrm{O}_{3}$ with $\mathrm{P}_{3} \mathrm{~cm}$ space group (\#185). All diffraction peaks match very well with standard XRD data of hexagonal $\mathrm{YMnO}_{3}$ (COD \#96-153-3979). The same structure was observed for $\mathrm{x}=0.8$ sample, only with a slight shift of the peaks to lower $2 \theta$ values due to the difference in the ionic radii of $\mathrm{Gd}^{3+}$ and $\mathrm{Y}^{3+}$ (ionic radius of $\mathrm{Gd}^{3+}$ in VII-fold coordination is $1.0 \AA$ and for $\mathrm{Y}^{3+}-0.96 \AA$ ) ${ }^{44}$. There was no mixture of hexagonal and orthorhombic structures observed as was suggested before for this composition ${ }^{35}$. With increasing the amount of $\mathrm{Gd}^{3+}$ the phase transition from hexagonal to orthorhombic structure can be clearly seen. In the XRD pattern of $\mathrm{x}=0.6$ sample the diffraction peaks belonging to both orthorhombic and hexagonal structures were detected. Employing Rietveld refinement for this sample, the ratio between these structures was 


\begin{tabular}{|l|l|l|l|l|}
\hline \multirow{2}{*}{ Sample } & \multicolumn{5}{|l|}{ Lattice parameters $(\AA)$} \\
\cline { 2 - 5 } & $\boldsymbol{a}$ & $\boldsymbol{b}$ & $\boldsymbol{c}$ & $\boldsymbol{V}$ \\
\hline $\mathrm{YMn}_{0.97} \mathrm{Fe}_{0.03} \mathrm{O}_{3}$ & $6.1438(4)$ & $6.1438(4)$ & $11.3724(0)$ & $371.76(0)$ \\
\hline $\mathrm{Y}_{0.8} \mathrm{Gd}_{0.2} \mathrm{Mn}_{0.97} \mathrm{Fe}_{0.03} \mathrm{O}_{3}$ & $6.1666(7)$ & $6.1666(7)$ & $11.3728(8)$ & $374.54(3)$ \\
\hline $\mathrm{h}-\mathrm{Y}_{0.6} \mathrm{Gd}_{0.4} \mathrm{Mn}_{0.97} \mathrm{Fe}_{0.03} \mathrm{O}_{3}$ & $6.1813(5)$ & $6.1813(5)$ & $11.3732(0)$ & $375.34(8)$ \\
\hline o- $\mathrm{Y}_{0.6} \mathrm{Gd}_{0.4} \mathrm{Mn}_{0.97} \mathrm{Fe}_{0.03} \mathrm{O}_{3}$ & $5.8266(8)$ & $7.3934(6)$ & $5.2764(1)$ & $227.30(4)$ \\
\hline $\mathrm{Y}_{0.4} \mathrm{Gd}_{0.6} \mathrm{Mn}_{0.97} \mathrm{Fe}_{0.03} \mathrm{O}_{3}$ & $5.8285(5)$ & $7.4035(0)$ & $5.2846(7)$ & $228.04(2)$ \\
\hline $\mathrm{Y}_{0.2} \mathrm{Gd}_{0.8} \mathrm{Mn}_{0.97} \mathrm{Fe}_{0.03} \mathrm{O}_{3}$ & $5.8307(7)$ & $7.4333(5)$ & $5.3030(2)$ & $229.84(4)$ \\
\hline $\mathrm{GdMn}_{0.97} \mathrm{Fe}_{0.03} \mathrm{O}_{3}$ & $5.8375(4)$ & $7.4384(8)$ & $5.3137(5)$ & $231.13(1)$ \\
\hline
\end{tabular}

Table 1. Cell parameters of $\mathrm{Y}_{\mathrm{x}} \mathrm{Gd}_{1-\mathrm{x}} \mathrm{Mn}_{0.97} \mathrm{Fe}_{0.03} \mathrm{O}_{3}$ samples.

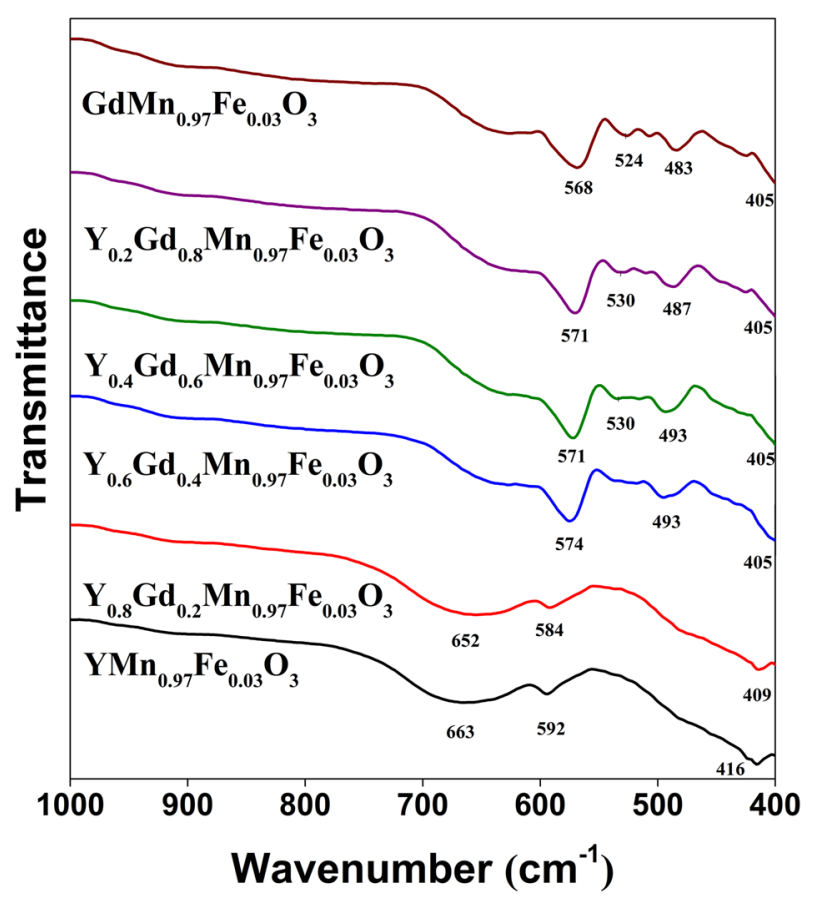

Figure 2. FT-IR spectra of $\mathrm{Y}_{\mathrm{x}} \mathrm{Gd}_{1-\mathrm{x}} \mathrm{Mn}_{0.97} \mathrm{Fe}_{0.03} \mathrm{O}_{3}$ samples.

calculated to be around 1 to 9 (10.2\%-hexagonal phase, $89.8 \%$-orthorhombic phase). These results show a significant shift towards orthorhombic structure in comparison with previous study. $\operatorname{In}^{33}$ the authors reported on the coexistence of nearly equal amounts of hexagonal and orthorhombic phases in $\mathrm{Y}_{0.6} \mathrm{Gd}_{0.4} \mathrm{MnO}_{3}$ ceramics sintered at $1350^{\circ} \mathrm{C}$. The structure of the samples with $\mathrm{x}=0-0.4$ was determined as orthorhombic with Pnma space group (\#62). Similarly, the increase in $\mathrm{Gd}^{3+}$ content caused the slight shift of the peaks to lower $2 \theta$ values. The narrow $2 \theta$ ranges of the XRD patterns showing gradual shift of the most intense diffraction peaks depending on chemical composition of synthesized powders are given in Figures S2 and S3. The specimens with ${ }^{57} \mathrm{Fe}$ isotope $\left(\mathrm{Y}_{\mathrm{x}} \mathrm{Gd}_{1-\mathrm{x}} \mathrm{Mn}_{0.97}{ }^{57} \mathrm{Fe}_{0.03} \mathrm{O}_{3}\right.$ ) demonstrated the identical structures (see Figure $\mathrm{S} 4$ ). No secondary phases were identified in the XRD patterns of all synthesized samples.

Rietveld refinement was performed for all synthesized samples. Calculated cell parameters and cell volumes are summarized in Table 1 and Table S1. It is seen that replacement of $\mathrm{Y}^{3+}$ by $\mathrm{Gd}^{3+}$ leads to the increase of unit cell parameters in the whole compositional range. Nearly linear dependence between chemical composition and cell parameters can be observed. The cell volume also increased with an increase of $\mathrm{Gd}^{3+}$ content. On the other hand, only minimal increase of $c$ parameter in hexagonal structure can be seen.

Figure 2 represents FT-IR spectra of $\mathrm{Y}_{\mathrm{x}} \mathrm{Gd}_{1-\mathrm{x}} \mathrm{Mn}_{0.97} \mathrm{Fe}_{0.03} \mathrm{O}_{3}$ specimens. Three absorption bands can be observed for hexagonal samples $(\mathrm{x}=1$ and 0.8$)$. The broad bands centered at $663 \mathrm{~cm}^{-1}(\mathrm{x}=1)$ and $652 \mathrm{~cm}^{-1}$ $(\mathrm{x}=0.8)$ can be associated with stretching mode of $\mathrm{Mn}-\mathrm{O}$ bond. This signal can be observed for all samples in the spectral range of $663-635 \mathrm{~cm}^{-1}$. The low intensity peaks at 592 and $584 \mathrm{~cm}^{-1}$ can also be attributed to the stretching vibration of $\mathrm{Mn}-\mathrm{O}$ bond. Lastly, the peaks at 416 and $415 \mathrm{~cm}^{-1}$ can be associated with vibrations of $\mathrm{Y}-\mathrm{O}$ bond, which were previously reported in ${ }^{45}$. Introduction of $\mathrm{Gd}^{3+}$ ions into the $\mathrm{YMn}_{0.97} \mathrm{Fe}_{0.03} \mathrm{O}_{3}$ structure obviously caused some changes in FT-IR spectra of the samples. Firstly, the sharp peak appeared in 574-568 $\mathrm{cm}^{-1}$ range can be clearly seen. Another lower intensity signal can be observed at $493-483 \mathrm{~cm}^{-1}$. Both of them are 


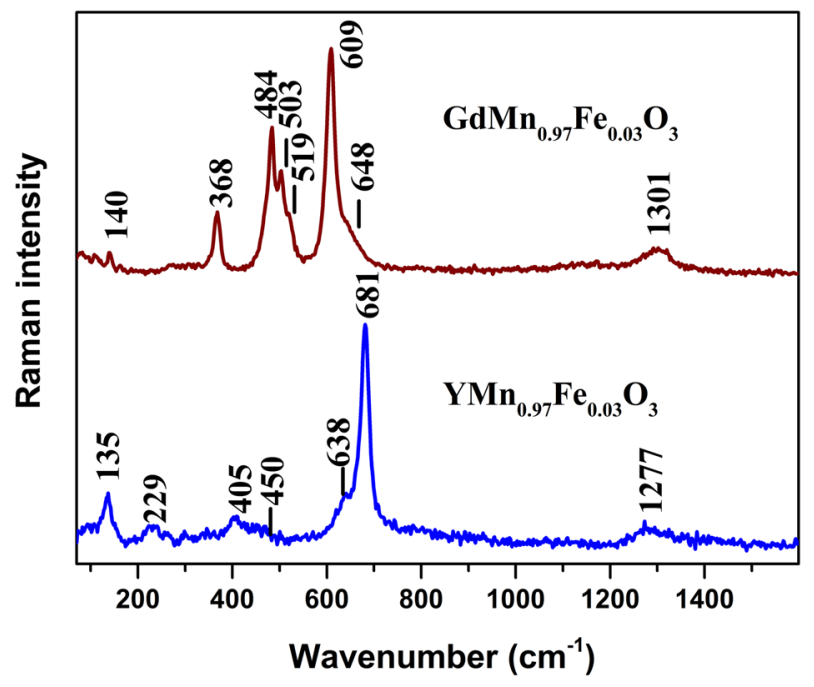

Figure 3. Raman spectra of polycrystalline $\mathrm{YMn}_{0.97} \mathrm{Fe}_{0.03} \mathrm{O}_{3}$ and $\mathrm{GdMn}_{0.97} \mathrm{Fe}_{0.03} \mathrm{O}_{3}$. Intensities are normalized to the intensity of the most intense band and spectra are shifted vertically for clarity. The excitation wavelength is $532 \mathrm{~nm}(0.6 \mathrm{~mW})$. Parameters of the bands were determined by fitting the experimental spectra using GRAMS/ $\mathrm{Al}$ software (version 8.0, https://www.thermofisher.com).

attributed to vibrations of $\mathrm{Gd}-\mathrm{O}$ bond ${ }^{46}$. Furthermore, appearance of two peaks can also be seen for the samples with orthorhombic structure. One of them is centered at $405 \mathrm{~cm}^{-1}$ for all orthorhombic samples, it is associated with $\mathrm{Mn}-\mathrm{O}$ vibrations ${ }^{47}$. The absorption band at $530 \mathrm{~cm}^{-1}$ is ascribed to $\mathrm{O}-\mathrm{Mn}-\mathrm{O}$ bending mode $\mathrm{e}^{48}$. The observed spectral changes can be explained by the fact that in hexagonal structure the $\mathrm{Mn}^{3+}$ ions are located in trigonal bipyramid with the coordination number of 5 , whereas in orthorhombic structure $\mathrm{Mn}^{3+}$ and six $\mathrm{O}^{2-}$ anions form octahedra (coordination number 6$)^{49}$.

Raman scattering provides detailed molecular level information on short range arrangement or local symmetry which is difficult to acquire by other techniques. The method is also sensitive to structural distortions. Figure 3 compares Raman spectra of polycrystalline $\mathrm{YMn}_{0.97} \mathrm{Fe}_{0.03} \mathrm{O}_{3}$ and $\mathrm{GdMn}_{0.97} \mathrm{Fe}_{0.03} \mathrm{O}_{3}$ samples. Detailed vibrational analysis of hexagonal $\mathrm{YMnO}_{3}$ was performed previously by Iliev et al. ${ }^{50}$. The most intense band of $\mathrm{YMn}_{0.97} \mathrm{Fe}_{0.03} \mathrm{O}_{3}$ compound visible at $681 \mathrm{~cm}^{-1}$ belongs to very small or zero splitting transverse optical (TO) and longitudinal optical $(\mathrm{LO})$ phonons with $\mathrm{A}_{1}$ symmetry considering the hexagonal structure. This mode is related to displacement of mainly oxygen atoms ${ }^{50}$. The shoulder at lower wavenumber side near $638 \mathrm{~cm}^{-1}$ is associated with TO-LO phonons of $\mathrm{E}_{1}$ symmetry ${ }^{50}$. Similarly, two low intensity bands located at $450 \mathrm{~cm}^{-1}$ (displacement of mainly oxygen and $\mathrm{Mn}$ atoms) and $405 \mathrm{~cm}^{-1}$ (displacement of mainly oxygen atoms) belong to $\mathrm{A}_{1}$ and $\mathrm{E}_{1}$ symmetry TO-LO modes, respectively. The low intensity band near $229 \mathrm{~cm}^{-1}$ can be assigned to $\mathrm{E}_{2}$ symmetry mode associated mainly with deformation vibration of oxygen and $\mathrm{Mn}$ atoms. Finally, the intense low frequency band at $135 \mathrm{~cm}^{-1}$ belongs to $\mathrm{E}_{2}$ symmetry mode related with motion of heavy $\mathrm{Y}$ atom. The low intensity feature near $1277 \mathrm{~cm}^{-1}$ is associated with overtone of oxygen stretching vibration ${ }^{51}$. Raman spectrum of $\mathrm{GdMn}_{0.97} \mathrm{Fe}_{0.03} \mathrm{O}_{3}$ differs considerably comparing with $\mathrm{YMn}_{0.97} \mathrm{Fe}_{0.03} \mathrm{O}_{3}$ (Fig. 3). Detailed assignments of Raman bands of orthorhombic perovskite $\mathrm{GdMnO}_{3}$ are provided in the publications of Illiev et al. ${ }^{52}$ and Oliveira et al. ${ }^{53}$. Thus, the most intense band at $609 \mathrm{~cm}^{-1}$ belongs to $\mathrm{B}_{2 \mathrm{~g}}(1) \mathrm{Jahn}$-Teller symmetry in-phase oxygen stretching mode. The $\mathrm{A}_{\mathrm{g}}(1)$ symmetry $\mathrm{MnO}_{6}$ bending mode is located at $503 \mathrm{~cm}^{-1}$. The strong band at $484 \mathrm{~cm}^{-1}$ is associated with $\mathrm{A}_{\mathrm{g}}(3)$ Jahn-Teller

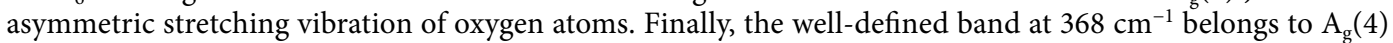
symmetry mode. This mode is associated with out-of-phase rotation of $\mathrm{MnO}_{6}$ octahedra ${ }^{52}$. The broad and low intensity band at $1301 \mathrm{~cm}^{-1}$ is related with overtone of oxygen stretching vibration ${ }^{51}$.

Figure 4a shows composition-dependent Raman spectra of $\mathrm{Y}_{\mathrm{x}} \mathrm{Gd}_{1-\mathrm{x}} \mathrm{Mn}_{0.97} \mathrm{Fe}_{0.03} \mathrm{O}_{3}$ compounds. The spectra corresponding to $\mathrm{x}=1$ and 0.8 are very similar indicating preservation of hexagonal $\mathrm{YMnO}_{3}$ structure in the case of $\mathrm{Y}_{0.8} \mathrm{Gd}_{0.2} \mathrm{Mn}_{0.097} \mathrm{Fe}_{0.03} \mathrm{O}_{3}$. Small distortions in the lattice are visible from the downshift of the intense $\mathrm{A}_{1}$ symmetry band from 681.3 to $678.7 \mathrm{~cm}^{-1}$, increase in relative intensities of $\mathrm{E}_{1}$ and $\mathrm{E}_{2}$ modes, and downshift of low frequency band associated with motion of $\mathrm{Y}^{3+}$ ion from 135.4 to $131.7 \mathrm{~cm}^{-1}$. Such frequency downshift correlates with larger ionic radius of $\mathrm{Gd}^{3+44}$.

However, drastic spectral changes take place after an additional introduction of $\mathrm{Gd}^{3+}$ to the level corresponding to $\mathrm{Y}_{0.6} \mathrm{Gd}_{0.4} \mathrm{MnO}_{3}$ composition. Characteristic vibrational bands of hexagonal $\mathrm{YMnO}_{3}$ completely disappeared. Instead, new bands characteristic to orthorhombic perovskite $\mathrm{GdMnO}_{3}$ appeared. Peak positions of all the observed bands downshift upon increasing the $\mathrm{Gd}^{3+}$ content corresponding to $\mathrm{x}=0.6$. Interestingly, further increase in $\mathrm{Gd}^{3+}$ amount does not affect the positions of intense bands at 609 or $484 \mathrm{~cm}^{-1}$ (Fig. 4b). However, different behavior was detected for the $\mathrm{A}_{\mathrm{g}}(4)$ mode near $368 \mathrm{~cm}^{-1}$ (Fig. 4c). Previously, it was demonstrated that phonon frequency of $\mathrm{A}_{\mathrm{g}}(4)$ mode depends linearly on the $\mathrm{MnO}_{6}$ hexagon rotation angle; frequency decreases with decreasing the angle ${ }^{52,54}$. 

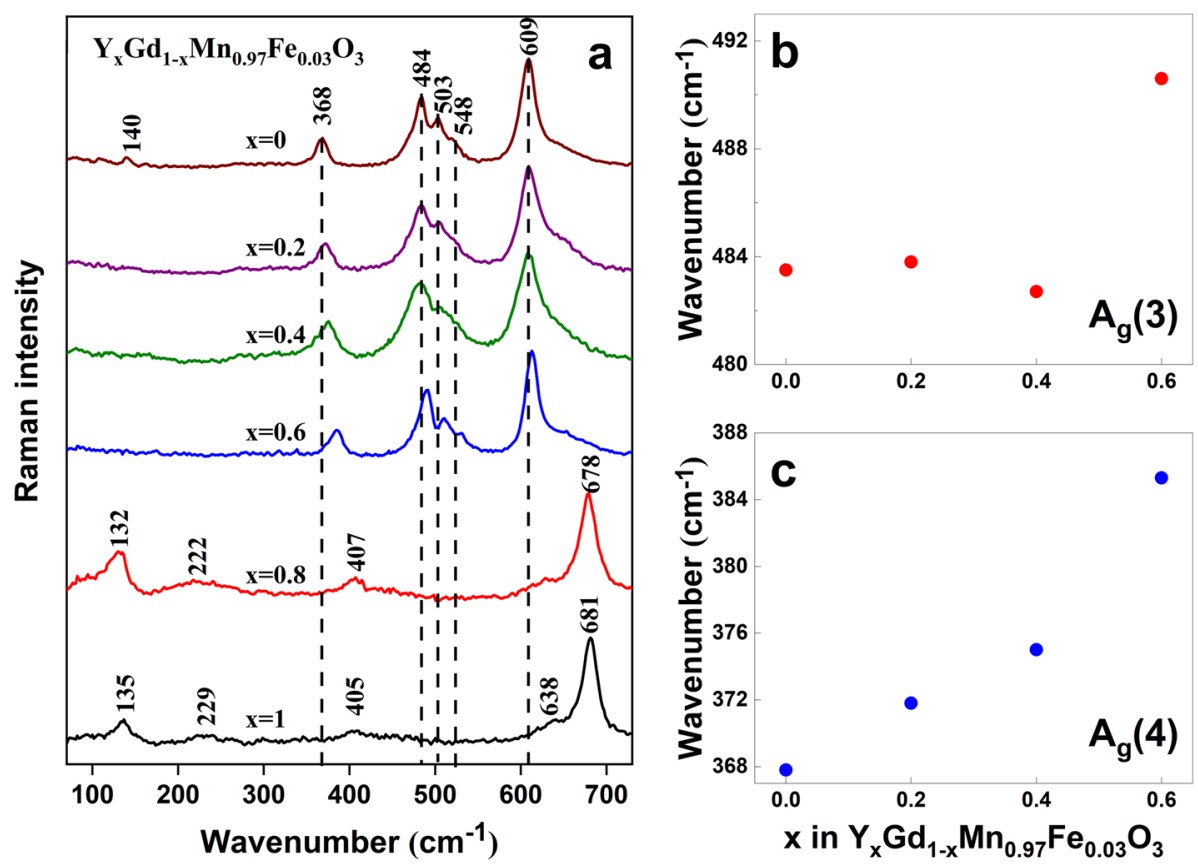

Figure 4. Composition dependent Raman spectra of polycrystalline $\mathrm{Y}_{\mathrm{x}} \mathrm{Gd}_{1-\mathrm{x}} \mathrm{Mn}_{0.97} \mathrm{Fe}_{0.03} \mathrm{O}_{3}$ compounds. Intensities are normalized to the intensity of the most intense band and spectra are shifted vertically for clarity. The excitation wavelength is $532 \mathrm{~nm}(0.6 \mathrm{~mW})$ (a). Composition variation of Raman wavenumber of $\mathrm{Y}_{\mathrm{x}} \mathrm{Gd}_{1-\mathrm{x}} \mathrm{Mn}_{0.097} \mathrm{Fe}_{0.03} \mathrm{O}_{3}$ compounds for $\mathrm{A}_{\mathrm{g}}(3)$ mode associated with asymmetric stretching vibration of oxygens (b) and $\mathrm{A}_{\mathrm{g}}(4)$ mode associated with out-of-phase rotation of $\mathrm{MnO}_{6}$ octahedra (c). Parameters of the bands were determined by fitting the experimental spectra using GRAMS/Al software (version 8.0, https://www.thermofish er.com).

Figure 5 shows SEM micrographs of $\mathrm{Y}_{\mathrm{x}} \mathrm{Gd}_{1-\mathrm{x}} \mathrm{Mn}_{0.097} \mathrm{Fe}_{0.03} \mathrm{O}_{3}$ powders annealed at $1100{ }^{\circ} \mathrm{C}$ and histograms of grain sizes with corresponding derivatives of cumulative distribution. It can be seen that $\mathrm{YMn}_{0.97} \mathrm{Fe}_{0.03} \mathrm{O}_{3}$ powder (Fig. 5a) possesses porous structure and consists of sintered aggregates which are composed of smaller and mostly uniform particles necked to each other. The histogram of grain size distribution (Fig. 5e) shows that grain size varies in the range of approximately $200-700 \mathrm{~nm}$ (around $90 \%$ of the grains; derivative of the cumulative distribution has maximum at $433 \mathrm{~nm}$ ). The SEM micrographs of $\mathrm{Y}_{0.6} \mathrm{Gd}_{0.4} \mathrm{Mn}_{0.097} \mathrm{Fe}_{0.03} \mathrm{O}_{3}$ and $\mathrm{Y}_{0.4} \mathrm{Gd}_{0.6} \mathrm{Mn}_{0.097} \mathrm{Fe}_{0.03} \mathrm{O}_{3}$ powders (Fig. 5b,c) show that particles having similar sizes and shape were formed, but slightly narrower size range was observed compared to the undoped sample (derivative maxima were obtained at $384 \mathrm{~nm}$ and $415 \mathrm{~nm}$ for $\mathrm{Y}_{0.6} \mathrm{Gd}_{0.4} \mathrm{Mn}_{0.097} \mathrm{Fe}_{0.03} \mathrm{O}_{3}$ and $\mathrm{Y}_{0.4} \mathrm{Gd}_{0.6} \mathrm{Mn}_{0.097} \mathrm{Fe}_{0.03} \mathrm{O}_{3}$, respectively). Porous structure was also maintained after the $\mathrm{Gd}$ was introduced as dopant. The different morphology was observed for the $\mathrm{GdMn}_{0.97} \mathrm{Fe}_{0.03} \mathrm{O}_{3}$ material (Fig. 5 d). As seen, $\mathrm{GdMn}_{0.97} \mathrm{Fe}_{0.03} \mathrm{O}_{3}$ powder possesses the smallest grains; and the histogram shows that around $90 \%$ of all grains are distributed in $100-500 \mathrm{~nm}$ range and around $70 \%$ of grains lie in considerably narrower range from 200 to $400 \mathrm{~nm}$ (derivative maximum at $320 \mathrm{~nm}$ ). This shows that with an increase in Gd content the average grain size of $\mathrm{Y}-\mathrm{Gd}-\mathrm{Mn}-\mathrm{Fe}-\mathrm{O}$ powders becomes smaller and suggests that the surface area and porosity of such ceramic materials could be tailored by changing chemical composition.

Dependence of the magnetization on applied magnetic field strength was studied for all samples and results are presented in Fig. 6. Linear magnetization dependences $m=\chi \mathrm{H}$ were observed for all $\mathrm{Y}_{\mathrm{x}} \mathrm{Gd}_{1-\mathrm{x}} \mathrm{Mn}_{0.97} \mathrm{Fe}_{0.03} \mathrm{O}_{3}$ solid solutions, which corresponds to paramagnetic state of the materials. Magnetic susceptibility of rare earth manganites is due to both Gd and Mn magnetic moments. The Curie-Weiss law $\chi_{\text {mol }}=N_{A} \mu_{e f f}{ }^{2} /\left(3 k_{B}(T-\theta)\right)$ was used to describe dependence of magnetic (molar) susceptibility, where $N_{A}$ and $k_{B}$ are the Avogadro number and Boltzmann constant on temperature. Application of Curie-Weiss law gave Curie-Weiss temperature $\theta=-421 \mathrm{~K}$ and $\theta \approx-35 \mathrm{~K}$ for $\mathrm{YMnO}_{3}$ and $\mathrm{GdMnO}_{3}{ }^{39,55}$, respectively. The effective magnetic moment $\mu_{\mathrm{eff}} \approx 9.4 \mu_{\mathrm{B}}$ of $\mathrm{GdMnO}_{3}$ was considerably larger than $\mu_{\text {eff }}=4.98 \mu_{\mathrm{B}}$ for $\mathrm{YMnO}_{3}$, where $\mu_{\mathrm{B}}$ is Bohr magneton. Therefore, the inclination magnetization lines increase with amount of $\mathrm{Gd}^{3+}$ because of both change in $\theta$ and $\mu_{\text {eff. }}$. It can be noticed that more significant decrease in magnetization values was observed along with transformation from orthorhombic structure to hexagonal (between $\mathrm{x}=0.6$ and 0.8 ).

Two alternative methods, quadrupole splitting distributions $\mathrm{P}(\Delta)$ with quadrupole splitting $\Delta$ step of $0.1 \mathrm{~mm} / \mathrm{s}$ and three or four doublets with freely variable parameters, were used for fitting to the room temperature Mössbauer spectra of $\mathrm{Y}_{\mathrm{x}} \mathrm{Gd}_{1-\mathrm{x}} \mathrm{Mn}_{0.97} \mathrm{Fe}_{0.03} \mathrm{O}_{3}$ (Fig. 7, Table 2). Quadrupole splitting distributions $\mathrm{P}(\Delta$ ) have peaks approximately at $1.60,1.58$ and $1.95 \mathrm{~mm} / \mathrm{s}$ for $\mathrm{x}=0,0.4$ and 1 , respectively. However, the distributions are wide; therefore, they indicate that Fe sites differ significantly by quadrupole splitting. The wider distribution of mixed $\mathrm{Y}_{0.4} \mathrm{Gd}_{0.6} \mathrm{Mn}_{0.97} \mathrm{Fe}_{0.03} \mathrm{O}_{3}$ in comparison to other two (Fig. 7b) can be explained by different influence of $\mathrm{Y}^{3+}$ and $\mathrm{Gd}^{3+}$ to the local crystal structure. In case of application of separate doublets, the most intense doublet has largest quadrupole splitting $\Delta$ (Table 2) which value can be explained by significant distortions of bipyramid $\mathrm{MnO}_{5}$ 


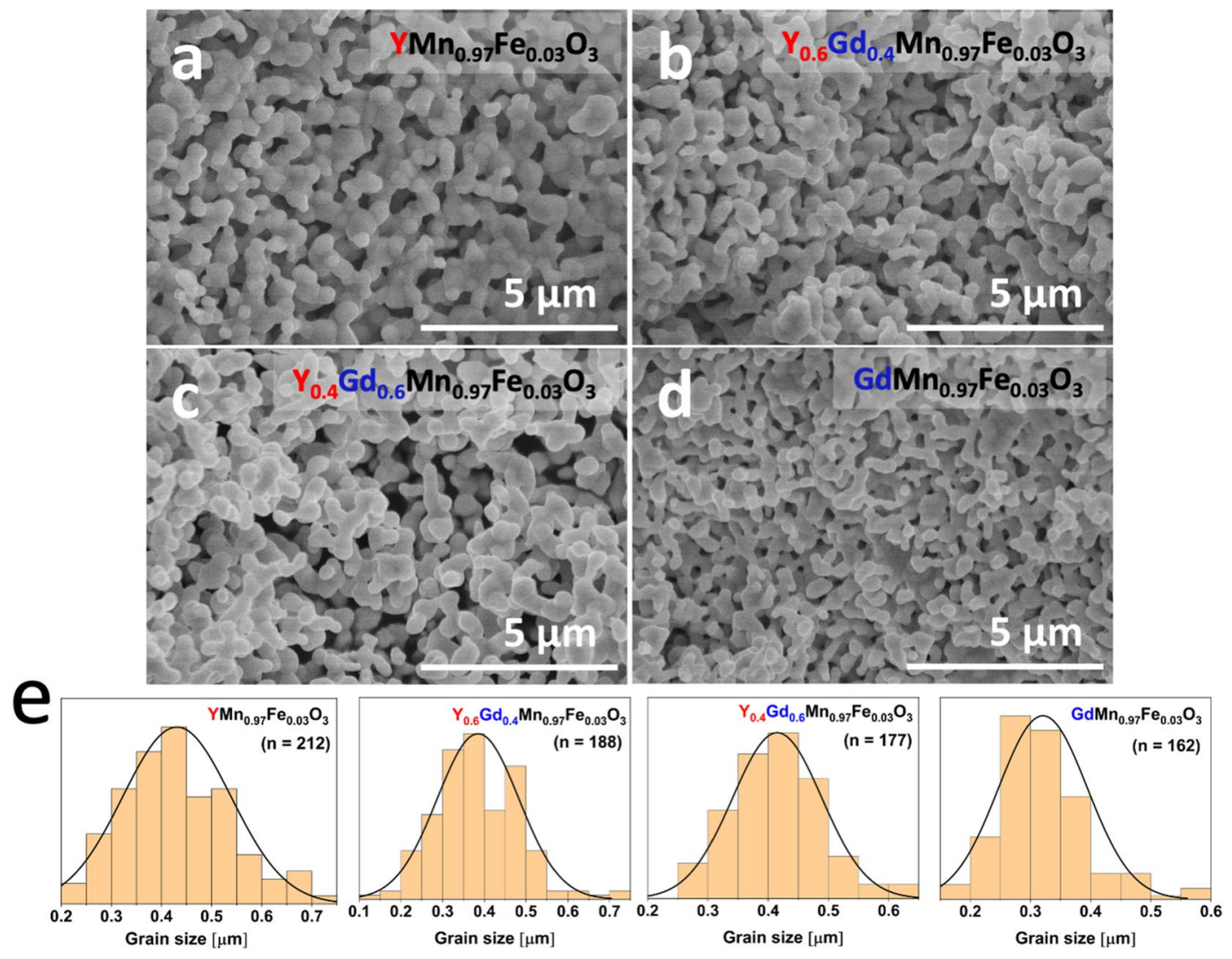

Figure 5. $\mathrm{SEM}$ micrographs of $\mathrm{YMn}_{0.97} \mathrm{Fe}_{0.03} \mathrm{O}_{3}(\mathbf{a}), \mathrm{Y}_{0.6} \mathrm{Gd}_{0.4} \mathrm{Mn}_{0.97} \mathrm{Fe}_{0.03} \mathrm{O}_{3}(\mathbf{b}), \mathrm{Y}_{0.4} \mathrm{Gd}_{0.6} \mathrm{Mn}_{0.97} \mathrm{Fe}_{0.03} \mathrm{O}_{3}(\mathbf{c})$ and $\mathrm{GdMn}_{0.97} \mathrm{Fe}_{0.03} \mathrm{O}_{3}$ (d) powders and histograms of grain sizes with corresponding derivatives of the cumulative distribution (e). Grain size distribution was calculated using ImageJ software (version $1.52 \mathrm{~s}$, https://imagej.nih. gov).

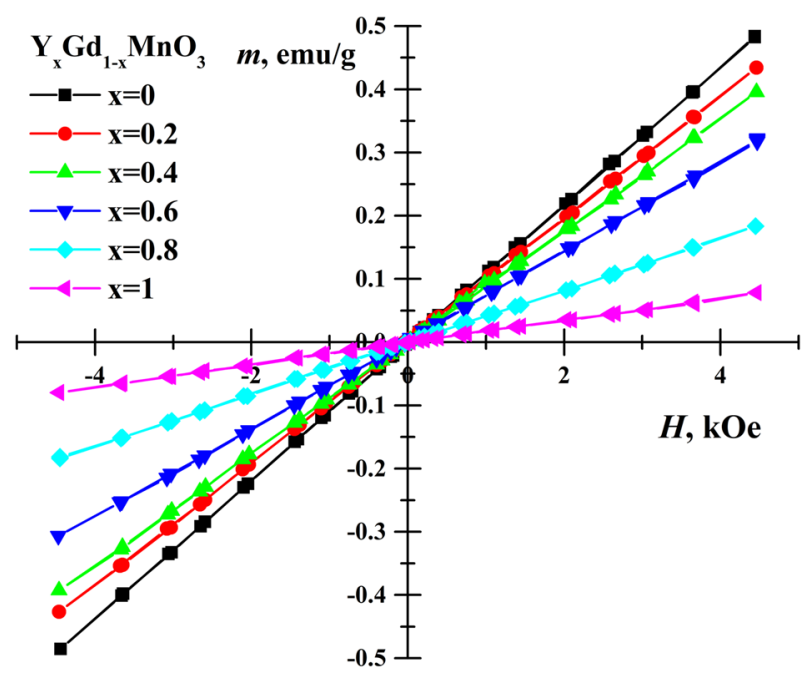

Figure 6. Magnetization hysteresis of $\mathrm{Y}_{\mathrm{x}} \mathrm{Gd}_{1-\mathrm{x}} \mathrm{Mn}_{0.97} \mathrm{Fe}_{0.03} \mathrm{O}_{3}$ samples at room temperature.

and octahedra $\mathrm{MnO}_{6}$ in hexagonal and orthorhombic $\mathrm{RMnO}_{3}$ ( $\mathrm{R}$ is rare earth) structures evaluating EFG components with application of point charge model $^{38,40,41}$. The doublets of smaller splitting should be attributed to more symmetric Fe sites. According to previous Mössbauer study of hexagonal $\mathrm{YFe}_{\mathrm{y}} \mathrm{Mn}_{1-\mathrm{y}} \mathrm{O}_{3}{ }^{38}$ the relative area of doublet with smaller $\Delta$ increased with Mn substitution by Fe. In the studies ${ }^{39,42}$ additional doublets at $y=0.1$; 0.2 were related with Fe atoms occupying Mn sites in nearest neighborhood. However, at $3 \% \mathrm{Mn}$ substitution the observed intensity of additional doublet was much larger than could be according to random occupation of 

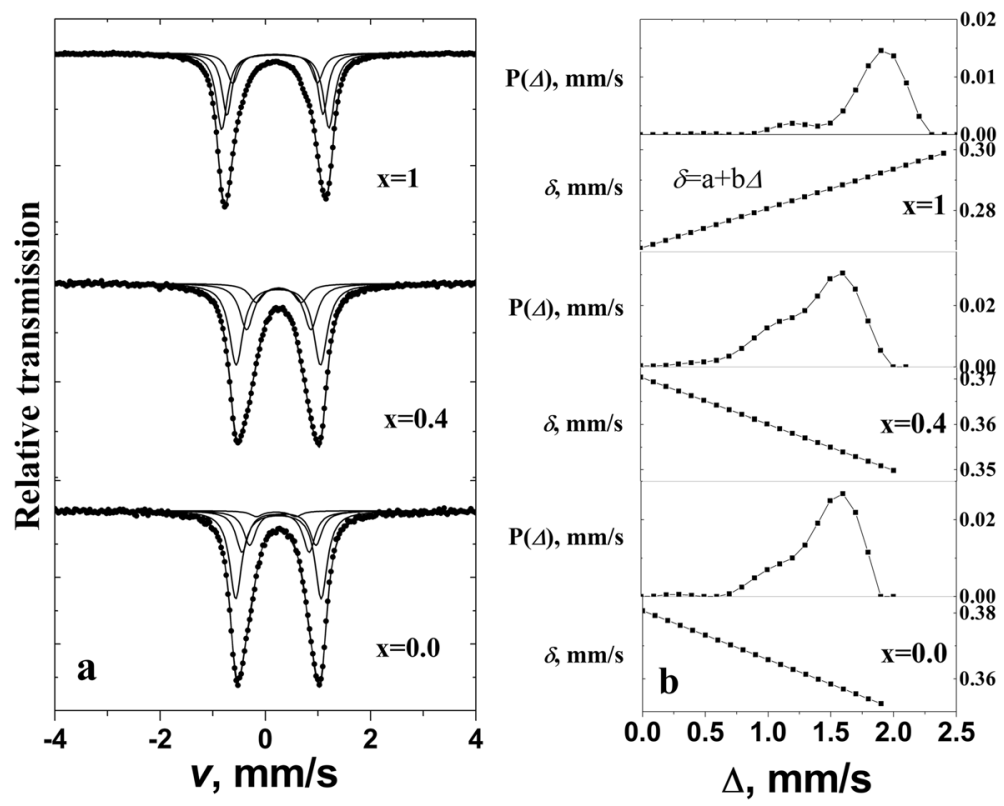

Figure 7. Mössbauer spectra of $\mathrm{Y}_{\mathrm{x}} \mathrm{Gd}_{1-\mathrm{x}} \mathrm{Mn}_{0.97} \mathrm{Fe}_{0.03} \mathrm{O}_{3}$ at room temperature fitted to doublets (a) and quadrupole splitting distribution $\mathrm{P}(\Delta)$ with dependence of isomer shift $\delta$ on quadrupole splitting $\Delta(\mathbf{b})$. Fitting of the spectra was performed using WinNormos-for-Igor software package (version 3.0, http://www.wisse l-gmbh.de).

\begin{tabular}{|l|l|l|l|l|l|}
\hline $\boldsymbol{x}$ & $\boldsymbol{S}, \boldsymbol{} \%$ & $\boldsymbol{\Gamma}, \mathbf{m m} / \mathbf{s}$ & $\boldsymbol{\delta}, \mathbf{m m} / \mathbf{s}$ & $\Delta, \mathbf{m m} / \mathbf{s}$ & $\mathbf{A}_{\mathbf{1 2}}$ \\
\hline 0 & 38 & $0.254 \pm 0.014$ & $0.356 \pm 0.001$ & $1.668 \pm 0.013$ & $0.952 \pm 0.004$ \\
\hline$\chi^{2}=1.12$ & 32 & $0.26 \pm 0.03$ & $0.362 \pm 0.003$ & $1.435 \pm 0.017$ & $0.952^{*}$ \\
\hline & 30 & $0.345 \pm 0.012$ & $0.376 \pm 0.003$ & $1.113 \pm 0.017$ & $0.952^{*}$ \\
\hline & average & & $0.364 \pm 0.001$ & $1.425 \pm 0.009$ & \\
\hline 0.4 & 34 & $0.27 \pm 0.01$ & $0.352 \pm 0.001$ & $1.662 \pm 0.013$ & $0.954 \pm 0.003$ \\
\hline$\chi^{2}=1.34$ & 29 & $0.30 \pm 0.04$ & $0.358 \pm 0.001$ & $1.403 \pm 0.016$ & $0.954^{*}$ \\
\hline & 37 & $0.41 \pm 0.01$ & $0.370 \pm 0.002$ & $1.065 \pm 0.015$ & $0.954^{*}$ \\
\hline & average & & $0.361 \pm 0.001$ & $1.425 \pm 0.009$ & \\
\hline 1 & 42 & $0.254 \pm 0.004$ & $0.298 \pm 0.001$ & $2.039 \pm 0.008$ & $0.983 \pm 0.002$ \\
\hline$\chi^{2}=1.53$ & 28 & $0.23 \pm 0.04$ & $0.290 \pm 0.001$ & $1.828 \pm 0.011$ & $0.983^{*}$ \\
\hline & 18 & $0.26 \pm 0.05$ & $0.293 \pm 0.001$ & $1.61 \pm 0.04$ & $0.983^{*}$ \\
\hline & 12 & $0.339 \pm 0.015$ & $0.282 \pm 0.002$ & $1.190 \pm 0.009$ & $0.983^{*}$ \\
\hline & average & & $0.292 \pm 0.001$ & $1.801 \pm 0.006$ & \\
\hline
\end{tabular}

Table 2. Parameters of doublets used to fit to $\mathrm{Y}_{\mathrm{x}} \mathrm{Gd}_{1-\mathrm{x}} \mathrm{Mn}_{0.97} \mathrm{Fe}_{0.03} \mathrm{O}_{3}$ Mössbauer spectra at room temperature: $S$ is relative area, $\Gamma$-linewidth, $\delta$-isomer shift relatively to $\alpha$-Fe at room temperature, $\Delta$-quadrupole splitting, $A_{12}$-line area ratio. ${ }^{\star}$ All equal.

six neighboring sites by Fe. Probably, the number of defects which increases in case of ultrafine structure, may also have similar influence. The isomer shift which is proportional to electron density at Fe nucleus ${ }^{37}$ depends on the Fe coordination number because of redistribution of electron charge. The isomer shift $\delta \approx 0.29 \mathrm{~mm} / \mathrm{s}$ of hexagonal $\mathrm{YMn}_{0.97} \mathrm{Fe}_{0.03} \mathrm{O}_{3}$ was smaller than $\delta \approx 0.36 \mathrm{~mm} / \mathrm{s}$ for orthorhombic phases $\mathrm{Y}_{\mathrm{x}} \mathrm{Gd}_{1-\mathrm{x}} \mathrm{Mn}_{0.97} \mathrm{Fe}_{0.03} \mathrm{O}_{3}$ with $\mathrm{x}=0,0.4$ (Table 2). Comparing hexagonal and orthorhombic phases it can be noticed that the dependence of isomer shift $\delta$ on quadrupole splitting $\Delta$ is of different sign (Fig. 7b). Moreover, it can be noted that the ratio of intensities of doublet lines $\mathrm{A}_{12}$ is slightly deviated from 1 (Table 2). Such effect can be caused by GoldanskiiKaryagin effect or sample anisotropy ${ }^{56}$.

According to low temperature Mössbauer spectra the magnetic ordering occurs at $\approx 36,39,70 \mathrm{~K}$ for $\mathrm{Y}_{\mathrm{x}} \mathrm{Gd}_{1-\mathrm{x}} \mathrm{Mn}_{0.97} \mathrm{Fe}_{0.03} \mathrm{O}_{3}$ with $\mathrm{x}=0,0.4$ and 1, respectively (Figs. 8 and 9a). It was previously observed for $\mathrm{YFe}_{\mathrm{y}} \mathrm{Mn}_{1-\mathrm{y}} \mathrm{O}_{3}$ that increasing $y$ from 0.02 to 0.2 magnetic ordering temperature decreased from 73 to $60 \mathrm{~K}^{38}$. Crystal structure (hexagonal or orthorhombic) of $\mathrm{RMnO}_{3}$ and $\mathrm{Mn}-\mathrm{O}-\mathrm{Mn}$ angle in orthorhombic $\mathrm{RMnO}_{3}$ affect magnetic ordering temperature according to ${ }^{38-43,55,57,58}$. Mössbauer spectrum of $\mathrm{YMn}_{0.97} \mathrm{Fe}_{0.03} \mathrm{O}_{3}$ measured at $12 \mathrm{~K}$ (Fig. 8a) was fitted to subspectra using Hamiltonian method as the quadrupole shifts were too large to 

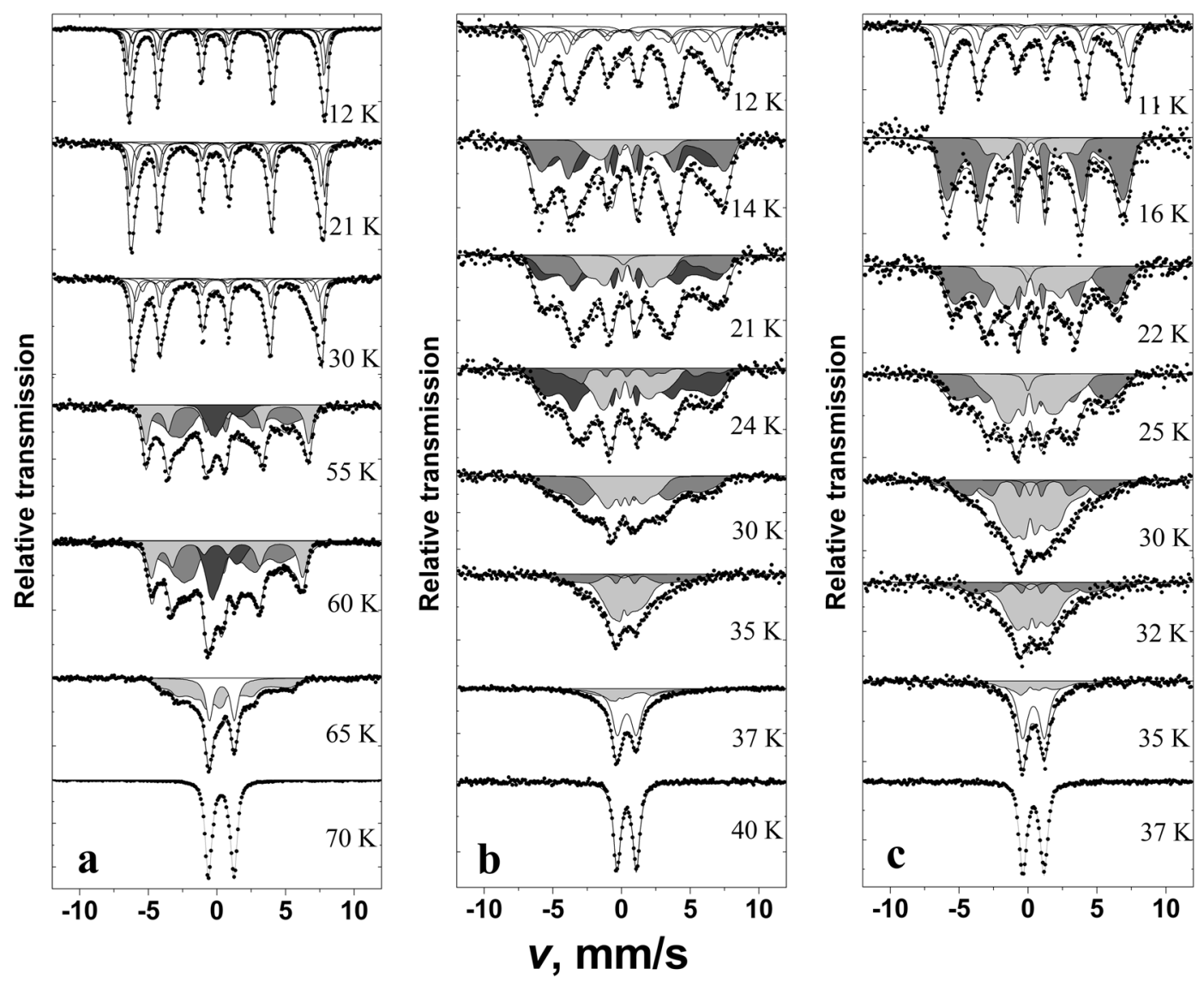

Figure 8. Mössbauer spectra of $\mathrm{YMn}_{0.97} \mathrm{Fe}_{0.03} \mathrm{O}_{3}(\mathbf{a}), \mathrm{Y}_{0.4} \mathrm{Gd}_{0.6} \mathrm{Mn}_{0.97} \mathrm{Fe}_{0.03} \mathrm{O}_{3}(\mathbf{b})$ and $\mathrm{GdMn}_{0.97} \mathrm{Fe}_{0.03} \mathrm{O}_{3}$ (c) at indicated temperatures. Fitting of the spectra was performed using WinNormos-for-Igor software package (version 3.0, http://www.wissel-gmbh.de).

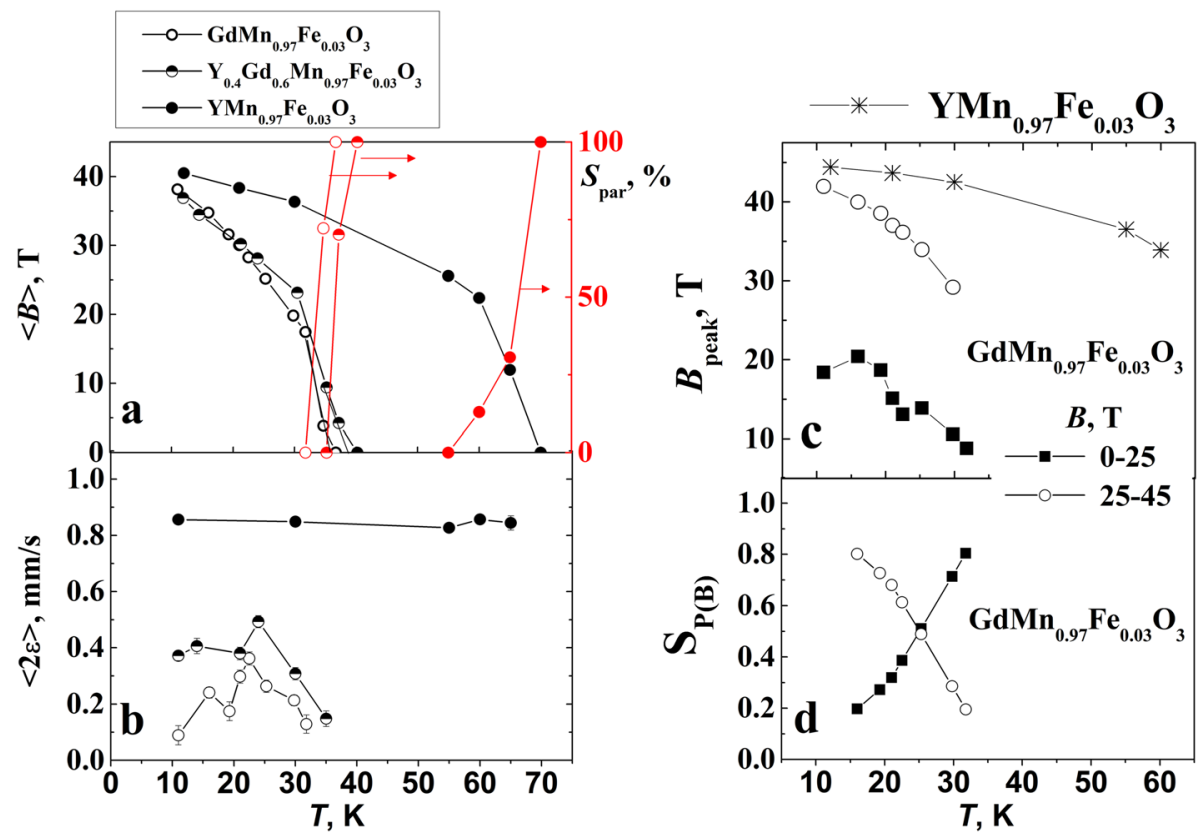

Figure 9. Dependence of average hyperfine field $\langle B\rangle$ (left), relative area of doublet $\mathrm{S}$ (right) (a), average quadrupole shift $<2 \varepsilon>$ (b) for $\mathrm{YMn}_{0.97} \mathrm{Fe}_{0.03} \mathrm{O}_{3}, \mathrm{Y}_{0.4} \mathrm{Gd}_{0.6} \mathrm{Mn}_{0.97} \mathrm{Fe}_{0.03} \mathrm{O}_{3}$, and $\mathrm{GdMn}_{0.97} \mathrm{Fe}_{0.03} \mathrm{O}_{3}$ on temperature. The peaks positions $(\mathbf{c})$ and the relative area of hyperfine field distributions $\mathrm{P}(B)(\mathrm{d})$ within $0-25$ and $25-45 \mathrm{~T}$ regions on temperature. 


\begin{tabular}{|c|c|c|c|c|c|c|c|c|}
\hline$x$ & $S, \%$ & $\Gamma \mathrm{mm} / \mathrm{s}$ & $\delta, \mathrm{mm} / \mathrm{s}$ & $2 \varepsilon, \mathrm{mm} / \mathrm{s}$ & $B, \mathrm{~T}$ & & & \\
\hline \multirow[t]{4}{*}{0} & 52 & $0.67 \pm 0.03$ & $0.493 \pm 0.006$ & $0.22 \pm 0.01$ & $42.33 \pm 0.08$ & - & - & - \\
\hline & 15 & $0.48 \pm 0.08$ & $0.463 \pm 0.013$ & $0.13 \pm 0.03$ & $39.80 \pm 0.13$ & - & - & - \\
\hline & 15 & $0.74 \pm 0.10$ & $0.50 \pm 0.02$ & $-0.06 \pm 0.05$ & $36.0 \pm 0.2$ & - & - & - \\
\hline & 18 & $2.1 \pm 0.4$ & $0.493^{*}$ & $-0.2 \pm 0.2$ & $20.0 \pm 0.8$ & - & - & - \\
\hline \multirow[t]{5}{*}{0.4} & 34 & $0.75 \pm 0.05$ & $0.481 \pm 0.007$ & $0.57 \pm 0.02$ & $43.6 \pm 0.1$ & - & - & - \\
\hline & 27 & $0.84 \pm 0.09$ & $0.481^{*}$ & $0.41 \pm 0.03$ & $39.9 \pm 0.2$ & - & - & - \\
\hline & 26 & $1.04 \pm 0.09$ & $0.481^{*}$ & $0.04 \pm 0.04$ & $35.1 \pm 0.2$ & - & - & - \\
\hline & 13 & $0.78 \pm 0.08$ & $0.481^{*}$ & $-0.64 \pm 0.05$ & $20.9 \pm 0.2$ & - & - & - \\
\hline & & & & $e Q V_{z z} / 2, \mathrm{~mm} / \mathrm{s}$ & & $\eta$ & $\theta,^{\circ}$ & $\phi,{ }^{\circ}$ \\
\hline \multirow[t]{4}{*}{1} & 42 & $0.36 \pm 0.01$ & $0.413 \pm 0.001$ & $-2.039^{*}$ & $42.97 \pm 0.01$ & $0.128 \pm 0.003$ & $90^{*}$ & $0^{*}$ \\
\hline & 28 & $0.33 \pm 0.01$ & $0.418 \pm 0.002$ & $-1.828^{\star}$ & $44.42 \pm 0.01$ & $0.066 \pm 0.004$ & $90^{*}$ & $0^{*}$ \\
\hline & 18 & $0.42 \pm 0.01$ & $0.423 \pm 0.004$ & $-1.61^{*}$ & $41.89 \pm 0.04$ & $0.018 \pm 0.009$ & $90^{*}$ & $90^{*}$ \\
\hline & 12 & $0.73 \pm 0.03$ & $0.405 \pm 0.012$ & $-1.19^{*}$ & $40.07 \pm 0.11$ & $0.38 \pm 0.04$ & $90^{*}$ & $90^{*}$ \\
\hline
\end{tabular}

Table 3. Parameters of sextets and Hamiltonian used to fit to $\mathrm{Y}_{\mathrm{x}} \mathrm{Gd}_{1-\mathrm{x}} \mathrm{Mn}_{0.97} \mathrm{Fe}_{0.03} \mathrm{O}_{3}$ Mössbauer spectra measured at 11-12 K: $S$ is relative area, $\Gamma$-linewidth, $\delta$-isomer shift relatively to $\alpha$-Fe at room temperature, $2 \varepsilon$-quadrupole shift, $e Q V_{z z} / 2$-term of quadrupole interaction, $B$-hyperfine field, $\eta$-asymmetry parameter, $\theta$ is the angle between magnetization and $\mathrm{EFG} z$ axis and $\varphi$ is the angle between magnetization projection and EFG $x$ axis. ${ }^{\star}$ Fixed.

consider only first order corrections (Eq. (2)). The term of quadrupole interaction was fixed according to room temperature data, $\left|e Q V_{z z}\right| / 2 \approx \Delta$ (Eq. (1), Tables 2 and 3). In case of hexagonal $\mathrm{YMn}_{0.97} \mathrm{Fe}_{0.03} \mathrm{O}_{3}$ the angle $\theta=90^{\circ}$ (Table 3) corresponds to EFG $z$ axis along crystal $c$ axis and the magnetization in $a b$ plane ${ }^{39,42,58,59}$. The angle $\varphi$ between magnetization projection into EFG $x y$ plane and $x$ axis had small influence on fitting quality and was fixed to 0 or $90^{\circ}$ trying to keep $0<\eta<1$ (Table 3). When asymmetry of $\mathrm{EFG}^{37}$ which expressed by parameter $\eta$ is small, according to Eq. (2) the spins of Fe lying at different angles in $a b$ plane resulted only in small changes in position of lines of Mössbauer spectrum and can be ascribed to the same subspectrum with slightly larger width of lines. Negative sign of $e Q V_{z z} / 2$ for $\mathrm{YMn}_{0.97} \mathrm{Fe}_{0.03} \mathrm{O}_{3}$ was in agreement with point charge calculations of EFG in case of hexagonal structure of rare earth manganites $\mathrm{YMnO}_{3}$ and $\mathrm{YbMnO}_{3}{ }^{38,40}$. Four subspectra (Table 3) which were fitted to Mössbauer spectrum of $\mathrm{YMn}_{0.97} \mathrm{Fe}_{0.03} \mathrm{O}_{3}$ measured at $12 \mathrm{~K}$ correspond to doublets because of fixing $e Q V_{z z} / 2$ and area ratios of subspectra. Largest difference in hyperfine field $B$ values of subspectra was $\approx 3 \mathrm{~T}$ indicating that the spectrum is broadened because of variation of both dipole magnetic and quadrupole interactions.

At lowest $11-12 \mathrm{~K}$ temperature the lines of Mössbauer spectra of $\mathrm{GdMn}_{0.97} \mathrm{Fe}_{0.03} \mathrm{O}_{3}$ and especially $\mathrm{Y}_{0.4} \mathrm{Gd}_{0.6} \mathrm{Mn}_{0.97} \mathrm{Fe}_{0.03} \mathrm{O}_{3}$ (Fig. 8b,c) were broader than those of $\mathrm{YMn}_{0.97} \mathrm{Fe}_{0.03} \mathrm{O}_{3}$. Four sextets with different parameters $B$ and $2 \varepsilon$ were fitted to Mössbauer spectra (Table 3). Quadrupole shifts of subspectra were smaller than those of $\mathrm{YMn}_{0.97} \mathrm{Fe}_{0.03} \mathrm{O}_{3}$ calculated according to Eq. (2) as shown in Fig. 9b, but hyperfine field $B$ of sextets varied from 20 to $\approx 42 \mathrm{~T}$. Such differences arise because of lower magnetic ordering temperature, crystal structure and spin ordering specifics.

Hyperfine field distributions $\mathrm{P}(B)$ were used for fitting to the Mössbauer spectra (Figs. 8 and 10) measured at higher then 11-12 K temperature up to transition to paramagnetic state. The shape of distributions is characterized by the features that are specific of different studied samples. Hyperfine distributions of $\mathrm{YMn}_{0.97} \mathrm{Fe}_{0.03} \mathrm{O}_{3}$ exhibited one peak within 35-45 T hyperfine field range which intensity decreased as temperature increased (Figs. 9c and 10a). Two peaks within 30-45 and 10-20 T hyperfine field regions (Fig. 9c) were characteristic of hyperfine field distributions $\mathrm{P}(B)$ of $\mathrm{GdMn}_{0.97} \mathrm{Fe}_{0.03} \mathrm{O}_{3}$. Broader hyperfine distributions of $\mathrm{Y}_{0.4} \mathrm{Gd}_{0.6} \mathrm{Mn}_{0.97} \mathrm{Fe}_{0.03} \mathrm{O}_{3}$ were observed because of different influence of $\mathrm{Y}$ and $\mathrm{Gd}$ on Fe local surrounding.

Dividing $\mathrm{P}(B)$ of $\mathrm{GdMn}_{0.97} \mathrm{Fe}_{0.03} \mathrm{O}_{3}$ into two parts (hyperfine field $B$ varies in the range of 0-25 and 25-45 T) it can be shown that intensities of high and low hyperfine field regions were approximately equal at $23 \mathrm{~K}$ (Fig. 9d) when the magnetic ordering transition in $\mathrm{GdMnO}_{3}$ occurs ${ }^{55,57,58,60} \cdot \mathrm{P}(B)$ within $25-45 \mathrm{~T}$ region dominates at low 11-12 K temperature (Fig. 10c, Table 3) when $\mathrm{Mn}$ spin order in $\mathrm{GdMnO}_{3}$ is A type antiferromagnetic. Incommensurate collinear (IC) sinusoidal amplitude modulated spin order (spin lying along $a$ axis of Pnma space group or $b$ axis in $P b n m$ ) at temperature higher than $23 \mathrm{~K}$ should lead to $\mathrm{P}(B)$ distribution in a wide hyperfine field range as observed for $\mathrm{FeVO}_{4}$ and orthorhombic Fe-doped $\mathrm{YbMnO}_{3}{ }^{43,61}$ with a maximum of $B \approx 38 \mathrm{~T}$. However, we observed the distribution of $\mathrm{P}(B)$ for $\mathrm{GdMn}_{0.97} \mathrm{Fe}_{0.03} \mathrm{O}_{3}$ having another peak at $B=10-20 \mathrm{~T}$ and minimum at $B=20-25 \mathrm{~T}$ which could be hardly related with IC sinusoidal amplitude modulated spin order. Certainly, Fe spin coupled by exchange interactions with nearest-neighbor Mn should be affected by Mn spin modulation. The exchange interactions of $\mathrm{Mn}-\mathrm{O}-\mathrm{Mn}$ in studied materials are ferromagnetic or antiferromagnetic depending on crystallographic directions $^{57}$. However, the doping with Fe may lead to some changes in spin order compared to $\mathrm{GdMnO}_{3}$ because of the exchange interactions of $\mathrm{Mn}-\mathrm{O}-\mathrm{Mn}$ being of different strength compared to ferromagnetic $\mathrm{Mn}-\mathrm{O}-\mathrm{Fe}$ or antiferromagnetic Fe-O-Fe exchange interactions. Structural differences in Fe sites which are indicated by quadrupole splitting changes at room temperature should also affect spin order. In case of $\mathrm{Y}_{0.4} \mathrm{Gd}_{0.6} \mathrm{Mn}_{0.97} \mathrm{Fe}_{0.03} \mathrm{O}_{3}$ three hyperfine field distributions $\mathrm{P}(B)$ were used (Fig. 10b). Two $\mathrm{P}(B)$ having different 

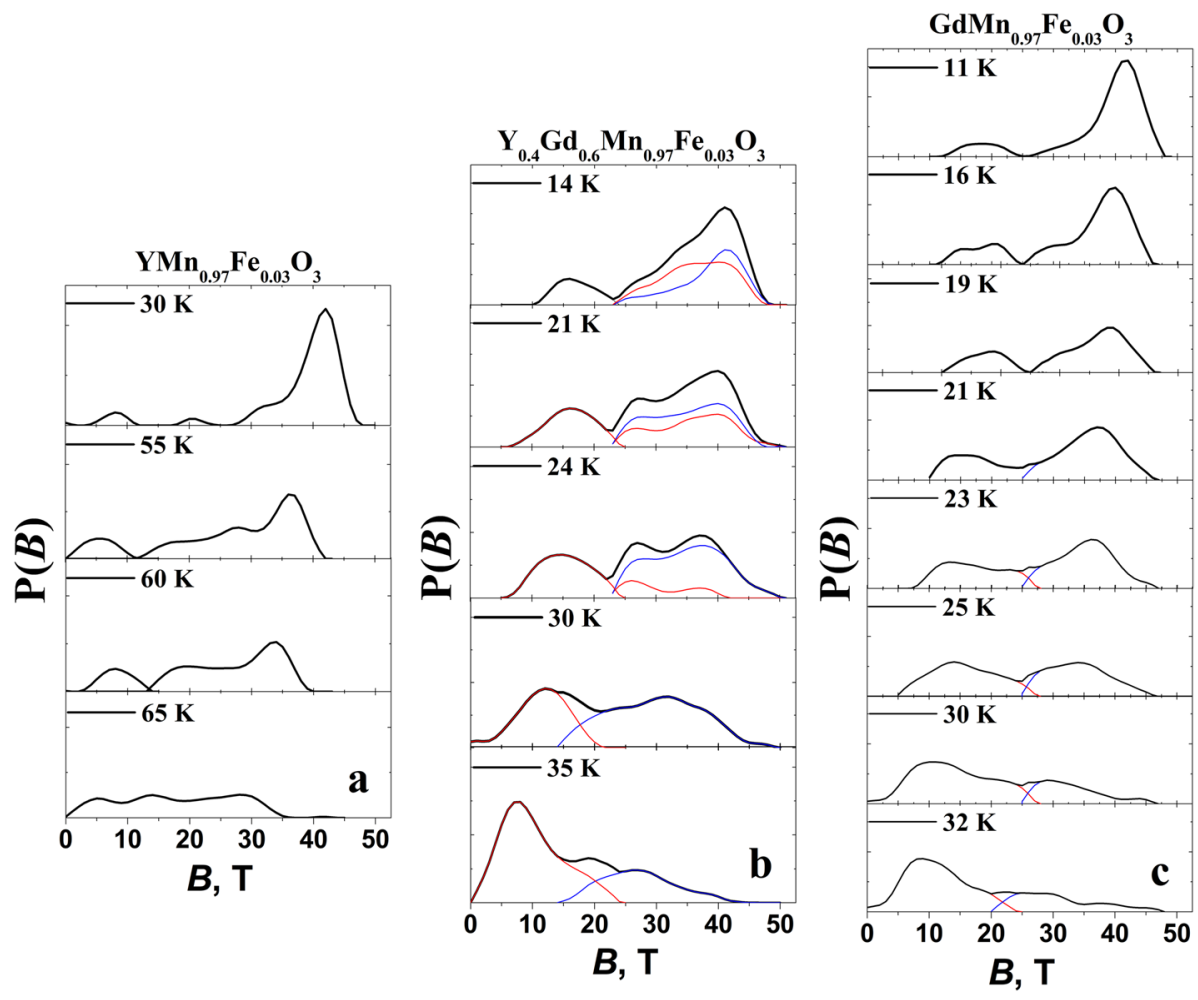

Figure 10. Hyperfine field distributions $\mathrm{P}(B)$ of $\mathrm{YMn}_{0.97} \mathrm{Fe}_{0.03} \mathrm{O}_{3}(\mathbf{a}), \mathrm{Y}_{0.4} \mathrm{Gd}_{0.6} \mathrm{Mn}_{0.97} \mathrm{Fe}_{0.03} \mathrm{O}_{3}(\mathbf{b})$, and $\mathrm{GdMn}_{0.97} \mathrm{Fe}_{0.03} \mathrm{O}_{3}(\mathbf{c})$. Fitting was performed using WinNormos-for-Igor software package (version 3.0, http:// www.wissel-gmbh.de).

quadrupole shift were needed in 25-45 T range, probably because of different $\mathrm{Y}$ and Gd influence on Fe local surrounding. In this case even more complicated spin order may exist.

Mössbauer spectra broadening and lines shift to center when temperature increases are explained by the increase in spin relaxation rate. According to Mössbauer spectra line shape theory ${ }^{62,63}$ the shape depends on population of stochastic spin states and transition rate between these states. Different stochastic states of Fe occur because of thermal excitations of spins, collective excitations such as magnons. At characteristic time of transition between stochastic states less than $10^{-7} \mathrm{~s}$ the shape of spectra starts to change (Mössbauer lines broaden) and at less than $10^{-9}-10^{-10} \mathrm{~s}$ averaged states (merged sextet lines to doublet/singlet at paramagnetic state) are observed. The change in peak positions $B_{\text {peak }}$ of $\mathrm{GdMn}_{0.97} \mathrm{Fe}_{0.03} \mathrm{O}_{3}$ within 25-45 and 0-25 T hyperfine field regions, when temperature increases, was rather slow similarly to that of one peak position of $\mathrm{YMn}_{0.97} \mathrm{Fe}_{0.03} \mathrm{O}_{3}$ in Figs. $9 \mathrm{c}$ and 10a. The gradual probability shift from the higher $B$ region with $\mathrm{P}(B)$ peak at $B=30-45 \mathrm{~T}$ to another one with 10-20 T peak with increasing temperature is associated with the decrease in hyperfine field because of thermal excitation and averaging of states. The spin order transitions can also contribute to lowering of hyperfine field, however, we do not observe any abrupt changes at $23 \mathrm{~K}$ (Fig. 9a).

\section{Conclusions}

A series of $\mathrm{Y}_{\mathrm{x}} \mathrm{Gd}_{1-\mathrm{x}} \mathrm{Mn}_{0.97} \mathrm{Fe}_{0.03} \mathrm{O}_{3}$ ( $\mathrm{x}$ from 0 to 1 with a step of 0.2 ) powders has been synthesized by an aqueous sol-gel method, and gadolinium substitution effects in yttrium manganite were investigated. Partial substitution of $\mathrm{Mn}^{3+}$ by ${ }^{57} \mathrm{Fe}^{3+}$ was performed in order to investigate deeper the structural properties of synthesized compounds applying Mössbauer spectroscopy. With increasing the $\mathrm{Gd}^{3+}$ content in the samples the crystal structure of $\mathrm{Y}_{\mathrm{x}} \mathrm{Gd}_{1-\mathrm{x}} \mathrm{Mn}_{0.97} \mathrm{Fe}_{0.03} \mathrm{O}_{3}$ gradually transformed from hexagonal to orthorhombic. The mixed phase was obtained when $\mathrm{x}=0.6$, whereas other compounds were determined to be monophasic. It was demonstrated that cell parameters increased almost linearly with increasing amount of $\mathrm{Gd}^{3+}$ in $\mathrm{Y}_{\mathrm{x}} \mathrm{Gd}_{1-\mathrm{x}} \mathrm{Mn}_{0.97} \mathrm{Fe}_{0.03} \mathrm{O}_{3}$. The results of FTIR and Raman spectroscopies were in good agreement with ones obtained by XRD analysis. According to SEM micrographs, the most of the samples were composed of porous aggregates which are organized of significantly smaller and mostly uniform particles necked to each other. The particle size varies in the range of approximately 100-600 nm depending on the chemical composition of gadolinium-substituted yttrium manganites. All synthesized compounds were characterized by paramagnetic behavior at room temperature; however, magnetization values were found to be dependent on chemical composition of the samples. Solid solutions with orthorhombic structure revealed higher magnetization values compared to those of hexagonal samples. According to Mössbauer spectroscopy data the magnetic ordering occurs at $\approx 36,39$ and $70 \mathrm{~K}$ for $\mathrm{Y}_{\mathrm{x}} \mathrm{Gd}_{1-\mathrm{x}} \mathrm{Mn}_{0.97} \mathrm{Fe}_{0.03} \mathrm{O}_{3}$ with $\mathrm{x}=0,0.4$ and 1 , respectively. For orthorhombic $\mathrm{GdMn}_{0.97} \mathrm{Fe}_{0.03} \mathrm{O}_{3}$ the change in types of antiferromagnetic ordering at $23 \mathrm{~K}$ is 
associated with the increase in hyperfine field probability of distribution within $25-45 \mathrm{~T}$ relatively to $10-20 \mathrm{~T}$ region which is more intense at higher temperature.

Received: 1 December 2020; Accepted: 21 January 2021

Published online: 03 February 2021

\section{References}

1. Dong, S. \& Liu, J. M. Recent progress of multiferroic perovskite manganites. Mod. Phys. Lett. B. 26, 1230004 (2012).

2. Tokura, Y. \& Tomioka, Y. Colossal magnetoresistive manganites. J. Magn. Magn. Mater. 200, 1-23 (1999).

3. Vopson, M. M. Fundamentals of multiferroic materials and their possible applications. Crit. Rev. Solid State Mater. Sci. 40, 223-250 (2015).

4. Tan, H. et al. Pressure and strain effects of hexagonal rare-earth manganites: A first-principles study. J. Phys. Condens. Matter. 28, 8 (2016).

5. Feng, S. M. et al. Determination of the intrinsic ferroelectric polarization in orthorhombic HoMnO3. New J. Phys. 12, 100411 (2010).

6. Ivanov, V. Y., Mukhin, A. A., Prokhorov, A. S., Balbashov, A. M. \& Ishakova, L. D. Magnetic properties and phase transitions in hexagonal DyMnO3 single crystals. Phys. Solid State. 48, 1726-1729 (2006).

7. Ren, C. Y. Atomic, electronic, and ferroelectric properties of manganite RMnO3 (R=Ho, Er, Tm, Lu) in hexagonal and orthorhombic phases. Phys. Rev. B Condens. Matter Mater. Phys. 79, 1-10 (2009).

8. Khomskii, D. Classifying multiferroics: Mechanisms and effects. Physics. 2, 20 (2009).

9. Gibbs, A. S., Knight, K. S. \& Lightfoot, P. High-temperature phase transitions of hexagonal YMnO3. Phys Rev. B - Condens. Matter Mater. Phys. 83, 1-9 (2011).

10. Zhou, J. S. et al. Hexagonal versus perovskite phase of manganite RMnO3 (R=Y, Ho, Er, Tm, Yb, Lu). Phys. Rev. B Condens. Matter Mater. Phys. 74, 1-7 (2006).

11. Medvedeva, J. E., Anisimov, V. I., Korotin, M. A., Mryasov, O. N. \& Freeman, A. J. Effect of Coulomb correlation and magnetic ordering on the electronic structure of two hexagonal phases of ferroelectromagnetic YMnO3. J. Phys. Condens. Matter. 12, 4947-4958 (2001).

12. Addabbo, T. et al. Gas sensing properties of YMnO3 based materials for the detection of NOx and CO. Sensors Actuators B Chem. 244, 1054-1070 (2017).

13. Wang, S. F., Yang, H., Xian, T. \& Liu, X. Q. Size-controlled synthesis and photocatalytic properties of YMnO3 nanoparticles. Catal. Commun. 12, 625-628 (2011).

14. Počuča-Nešić, M. et al. Mechanochemical synthesis of yttrium manganite. J. Alloys Compd. 552, 451-456 (2013).

15. Uusi-Esko, K., Malm, J. \& Karppinen, M. Atomic layer deposition of hexagonal and orthorhombic YMnO3 thin films. Chem. Mater. 21, 5691-5694 (2009).

16. Brinks, H. W., Fjellvåg, H. \& Kjekshus, A. Synthesis of metastable perovskite-type YMnO3 and HoMnO3. J. Solid State Chem. 129, 334-340 (1997).

17. Kim, K. T. \& Kim, C. I. The effects of drying temperature on the crystallization of YMnO3 thin films prepared by sol-gel method using alkoxides. J. Eur. Ceram. Soc. 24, 2613-2617 (2004).

18. Iliev, M., Lee, H. \& Popov, V. Raman- and infrared-active phonons in hexagonal: Experiment and lattice-dynamical calculations. Phys. Rev. B Condens. Matter Mater. Phys. 56, 2488-2494 (1997).

19. Kumar, R. D. \& Jayavel, R. Low temperature hydrothermal synthesis and magnetic studies of YMnO3 nanorods. Mater. Lett. 113, 210-213 (2013).

20. Asakura, Y., Miyake, A. \& Yin, S. Improvement of the O2 storage/release rate of YMnO3 nanoparticles synthesized by the polymerized complex method. Dalton Trans. 49, 966-971 (2020).

21. Alqat, A. et al. Synthesis of hexagonal YMnO3 from precursor obtained by the glycine-nitrate process. Ceram. Int. 39, 3183-3188 (2013).

22. Wang, X. L. et al. Magnetic and optical properties of multiferroic GdMnO3 nanoparticles. J. Appl. Phys. 107, 766 (2010).

23. Li, X. et al. Novel multiferroicity in GdMnO3 thin films with self-assembled nano-twinned domains. Sci. Rep. 4, 7019 (2014).

24. Lee, D. et al. Epitaxial stabilization of artificial hexagonal GdMnO3 thin films and their magnetic properties. Appl. Phys. Lett. 90, 2-5 (2007).

25. Zhang, X. et al. Investigation on the pyroelectric property of polycrystalline GdMnO3. Appl. Phys. Lett. 104, 062903 (2014).

26. Kimura, T., Lawes, G., Goto, T., Tokura, Y. \& Ramirez, A. P. Magnetoelectric phase diagrams of orthorhombic RMnO3 (R=Gd, Tb, and Dy). Phys. Rev. B Condens. Matter Mater. Phys. 71, 1-13 (2005).

27. Negi, P., Dixit, G., Agrawal, H. M. \& Srivastava, R. C. Structural, optical and magnetic properties of multiferroic GdMnO3 nanoparticles. J. Supercond. Nov. Magn. 26, 1611-1615 (2013).

28. Samantaray, S. et al. Correlation between structural, electrical and magnetic properties of GdMnO3 bulk ceramics. J. Magn. Magn. Mater. 339, 168-174 (2013).

29. Ferreira, W. S. et al. Spin-phonon coupling and magnetoelectric properties: EuMnO3 versus GdMnO3. Phys. Rev. B - Condens. Matter Mater. Phys. 79, 1-10 (2009).

30. Prakash, B. J., Kumar, K. N. \& Buddhudu, S. Thermal, magnetic and electrical properties of multiferroic GdMnO 3 nano particles by a co-precipitation method. Ferroelectr. Lett. Sect. 39, 104-116 (2012).

31. Mukhin, A. A. et al. Phase transitions and spin excitations in new multiferroics with modulated magnetic structure. Bull. Russ. Acad. Sci. Phys. 7, 1617-1619 (2007).

32. Ramaiyan Mahadevan, S., Varadarajan, S., Awasthi, A. M. \& Natarajan, S. Studies on dielectric relaxation in ceramic multiferroic Gd1-xYxMnO3. J. Am. Ceram. Soc. 100, 2596-2603 (2017).

33. Vilarinho, R. et al. Scaling spin-phonon and spin-spin interactions in magnetoelectric Gd1-xYxMnO3. J. Solid State Chem. 228, 76-81 (2015).

34. Vilarinho, R. et al. Dzyaloshinskii-Moriya nature of ferroelectric ordering in magnetoelectric Gd1- xYxMnO3 system. Solid State Commun. 208, 34-40 (2015).

35. Bos, J. W. G., Van Aken, B. B. \& Palstra, T. T. M. Site disorder induced hexagonal-orthorhombic transition in Y3+1-xGd3+xMnO3. Chem. Mater. 13, 4804-4807 (2001).

36. Karoblis, D. et al. Sol-gel synthesis, structural, morphological and magnetic properties of BaTiO3-BiMnO3 solid solutions. Ceram. Int. 46, 16459-16464 (2020).

37. Chen, Y. L. \& Yang, D. P. Mössbauer Effect in Lattice Dynamics: Experimental Techniques and Applications (Wiley-VCH, New York, 2007).

38. Zaghrioui, M., Greneche, J. M., Autret-Lambert, C. \& Gervais, M. Effect of Fe substitution on multiferroic hexagonal YMnO3. J. Magn. Magn. Mater. 323, 509-514 (2011). 
39. Sharma, N., Das, A., Prajapat, C. L. \& Meena, S. S. Spin reorientation behavior in YMn1- xMxO3 (M= Ti, Fe, Ga; $\mathrm{x}=0$, 0.1). J. Magn. Magn. Mater. 348, 120-127 (2013).

40. Salama, H. A., Stewart, G. A., Ryan, D. H., Elouneg-Jamroz, M. \& Edge, A. V. J. A Mössbauer spectroscopy investigation of h-YbMnO3. J. Phys. Condens. Matter. 20, 255213 (2008).

41. Stewart, G. A. et al. A Mössbauer investigation of orthorhombic phase YbMnO3. Hyperfine Interact. 230, 195-203 (2015).

42. Sharma, N. et al. Magnetic and dielectric behavior in YMn1-xFexO3 ( $\mathrm{x} \leq 0.5)$. J. Appl. Phys. 115, 213911 (2014).

43. Duttine, M. et al. Modulated magnetic structure in 57Fe doped orthorhombic YbMnO3: A Mössbauer study. AIP Adv. 9, 35008 (2019).

44. Shannon, R. D. Revised effective ionic radii and systematic studies of interatomic distances in halides and chalcogenides. Acta Crystallogr. Sect. A. 32, 751-767 (1976).

45. Vishnuvardhan, T. K., Kulkarni, V. R., Basavaraja, C. \& Raghavendra, S. C. Synthesis, characterization and a.c. conductivity of polypyrrole/Y2O3 composites. Bull. Mater. Sci. 29, 77-83 (2006).

46. Guo, H. et al. Visible upconversion in rare earth ion-doped Gd2O3 nanocrystals. J. Phys. Chem. B. 108, 19205-19209 (2004).

47. Subba Rao, G. V. \& Rao, C. N. R. Infrared and electronic spectra of rare earth perovskites. Ortho- Chromites, -Manganites and Ferrites. Appl. Spectrosc. 24, 436-444 (1970).

48. Negi, P. et al. Tuning of structural and optical properties by sintering of multiferroic GdMnO3 precursor. Ferroelectrics 519, 200-208 (2017).

49. Yakel, H. L. \& Koehler, W. C. On the crystal structure of the manganese (III) trioxides of the heavy lanthanides and yttrium. Acta cryst. 16, 957 (1963).

50. Iliev, M. N. et al. Raman-and infrared-active phonons in hexagonal YMnO3: experiment and lattice-dynamical calculations. Phys. Rev. B. 56, 2488 (1997).

51. Andreasson, J. et al. Electron-phonon interactions in perovskites containing $\mathrm{Fe}$ and $\mathrm{Cr}$ studied by Raman scattering using oxygenisotope and cation substitution. Phys. Rev. B. 78, 235103 (2008).

52. Iliev, M. N. et al. Distortion-dependent Raman spectra and mode mixing in $\mathrm{RMnO} 3$ perovskites ( $\mathrm{R}=\mathrm{La}, \mathrm{Pr}, \mathrm{Nd}, \mathrm{Sm}, \mathrm{Eu}, \mathrm{Gd}, \mathrm{Tb}$, Dy, Ho, Y). Phys. Rev. B. 73, 64302 (2006).

53. Oliveira, J. et al. Structural and insulator-to-metal phase transition at $50 \mathrm{GPa}$ in GdMnO3. Phys. Rev. B. 85, 52101 (2012).

54. Iliev, M. N. et al. Raman spectroscopy of orthorhombic perovskitelike YMnO3 and LaMnO3. Phys. Rev. B. 57, 2872 (1998).

55. Hemberger, J. et al. Complex interplay of $3 \mathrm{~d}$ and $4 \mathrm{f}$ magnetism in Lal-xGdxMnO3. Phys. Rev. B. 70, 24414 (2004).

56. Pfannes, H. D. \& Gonser, U. Goldanskii-Karyagin effect versus preferred orientations (texture). Appl. Phys. 1, 93-102 (1973).

57. Kimura, T. et al. Distorted perovskite with e g 1 configuration as a frustrated spin system. Phys. Rev. B. 68, 60403 (2003).

58. Wang, K. F., Liu, J. M. \& Ren, Z. F. Multiferroicity: The coupling between magnetic and polarization orders. Adv. Phys. 58, 321-448 (2009).

59. Lima, A. F. \& Lalic, M. V. Ground-state magnetic structure of hexagonal YMnO3 compound: A non-collinear spin density functional theory study. J. Magn. Magn. Mater. 416, 236-240 (2016).

60. Mochizuki, M. \& Furukawa, N. Microscopic model and phase diagrams of the multiferroic perovskite manganites. Phys. Rev. B. 80, 134416 (2009).

61. Colson, D., Forget, A. \& Bonville, P. The modulated antiferromagnetic structures in multiferroic FeVO4: A 57Fe Mössbauer spectroscopy investigation. J. Magn. Magn. Mater. 378, 529-534 (2015).

62. Blume, M. Stochastic theory of line shape: generalization of the Kubo-Anderson model. Phys. Rev. 174, 351 (1968).

63. Blume, M. J. \& Tjon, A. Mössbauer spectra in a fluctuating environment. Phys. Rev. 165, 446 (1968).

\section{Acknowledgements}

This work was supported by a Research grant BUNACOMP (No. S-MIP-19-9) from the Research Council of Lithuania (LMTLT). G.N. gratefully acknowledges the Center of Spectroscopic Characterization of Materials and Electronic/Molecular Processes (SPECTROVERSUM Infrastructure) for use of Raman spectrometer. E.G. gratefully acknowledges financial support by the Swedish Research Council for Environment, Agricultural Sciences and Spatial Planning (FORMAS) Project "Utilization of solid inorganic waste from the aquaculture industry as wood reinforcement material for flame retardancy" (grant no. 2018-01198). The World Federation of Scientists is highly acknowledged for a National Scholarship to A.Z.

\section{Author contributions}

Conceptualization, A.Z. and A.K.; methodology, D.K. and A.Z.; formal analysis, D.K., A.Z. E.G., K.M., D.B., G.N. A.B.; investigation, D.K., A.Z. E.G., K.M., D.B., G.N., A.B.; resources, E.G., A.K.; writing-original draft preparation, D.K.; writing - review and editing, A.K.; supervision, A.K.; funding acquisition, E.G., A.B. All authors reviewed the manuscript.

\section{Competing interests}

The authors declare no competing interests.

\section{Additional information}

Supplementary Information The online version contains supplementary material available at https://doi. org/10.1038/s41598-021-82621-6.

Correspondence and requests for materials should be addressed to A.Z.

Reprints and permissions information is available at www.nature.com/reprints.

Publisher's note Springer Nature remains neutral with regard to jurisdictional claims in published maps and institutional affiliations. 
(c) (i) Open Access This article is licensed under a Creative Commons Attribution 4.0 International cc) License, which permits use, sharing, adaptation, distribution and reproduction in any medium or format, as long as you give appropriate credit to the original author(s) and the source, provide a link to the Creative Commons licence, and indicate if changes were made. The images or other third party material in this article are included in the article's Creative Commons licence, unless indicated otherwise in a credit line to the material. If material is not included in the article's Creative Commons licence and your intended use is not permitted by statutory regulation or exceeds the permitted use, you will need to obtain permission directly from the copyright holder. To view a copy of this licence, visit http://creativecommons.org/licenses/by/4.0/.

(C) The Author(s) 2021 